\title{
On the crystallographic characteristics of nanobainitic steel
}

\author{
Hossein Beladi ${ }^{1}$, Vahid Tari ${ }^{2}$, Ilana B. Timokhina ${ }^{1}$, Pavel Cizek $^{1}$, Gregory S. Rohrer ${ }^{2}$, Anthony D. \\ Rollett $^{2}$ and Peter D. Hodgson ${ }^{1}$ \\ ${ }^{1}$ Institute for Frontier Materials, Deakin University, Geelong, VIC 3216, Australia \\ ${ }^{2}$ Department of Materials Science and Engineering, Carnegie Mellon University, Pittsburgh, PA 15213-3890, USA
}

\begin{abstract}
This study aims to elucidate the crystallographic characteristics of bainite transformed in a temperature range of $200-350^{\circ} \mathrm{C}$, where a nanobainitic structure is formed. The microstructure, consisting of bainitic ferrite laths and retained austenite, became significantly refined and its crystallographic arrangement changed with a decrease in the phase transformation temperature. At $200-250^{\circ} \mathrm{C}$, the bainite packets mostly consisted of one or more blocks (i.e. bainitic ferrite laths and retained austenite lamellae) with different orientations, having a common habit plane. Some of the bainitic laths formed in this temperature range were composed of small segments with similar orientations, while others displayed a ragged morphology with small protrusions, suggesting face-to-face and face-to-edge sympathetic nucleation, respectively. At $300-350^{\circ} \mathrm{C}$, the latter nucleation mechanism appeared to be dominant, as bainite packets mostly consisted of two sets of bainitic ferrite laths with similar orientations and inclined to each other (i.e. having different habit planes). In general, all rational orientation relationships (ORs) ranging from Kurdjumov-Sachs (K-S) through to NishiyamaWassermann $(\mathrm{N}-\mathrm{W})$ were observed within the transformation temperature range. The N-W OR was dominant at $350^{\circ} \mathrm{C}$ and progressively changed towards the $\mathrm{K}-\mathrm{S} \mathrm{OR}$, which was prevalent at $200^{\circ} \mathrm{C}$. The five-parameter crystallographic approach was used to statistically measure the habit plane distributions for both bainitic ferrite and retained austenite, which were generally found to be irrational and exhibited a significant anisotropy. The bainitic ferrite interface plane distribution displayed a wide peak spreading from (101) to (535). The retained austenite revealed a maximum at the (111) orientation, extending towards the (554).
\end{abstract}

Keywords: habit plane, crystallography, nanobainitic steel, bainitic transformation, orientation relationship 


\section{Introduction}

Bainite transformation taking place in the iron-based alloys in the intermediate temperature regime between polygonal ferrite and martensite is of a major technological significance, as the bainite phase represents an important microstructure constituent in a range of modern steels. Bainite consists of ferrite crystals (e.g., laths), containing medium to high density of dislocations, arranged in complex packets $[1,2]$. The crystallography of bainite is generally described through different orientation relationships between parent austenite and bainitic ferrite, ranging from Nishiyama-Wassermann $(\mathrm{N}$ W) through Kurdjumov-Sachs (K-S). This theoretically results in the formation of 12 or 24 distinct crystallographic equivalent variants/orientations from a given parent austenite crystal depending on the orientation relationship. The inter-variant boundaries, resulted from the impingement of these variants, play a significant role in controlling the crack propagation path and consequently the fracture toughness of the steel $[3,4]$.

New advances in bainitic steels led to the development of nano-structured bainite consisting of very fine bainitic ferrite laths $(\sim 50 \mathrm{~nm})$ and retained austenite films between them, which offers a unique combination of mechanical properties. The composition of nanobainitic steels was designed based on the thermodynamic approach to obtain a very fine bainitic microstructure at relatively low isothermal transformation temperature regime (i.e., as low as $150^{\circ} \mathrm{C}$ ) [5-7]. These steels usually contain high amount carbon content (i.e., $>0.7$ wt \%) and other alloying elements (e.g., $\mathrm{Si}, \mathrm{Mn}, \mathrm{Co}, \mathrm{Al}$, ...), which significantly slow down the bainite formation kinetics and result in the transformation taking up to 14 days to complete. The slow phase transformation kinetics, as well as the presence of a relatively high volume fraction of retained austenite (20-50\%) [8], offers an opportunity to undertake a direct examination of various aspects of the bainitic phase transformation. The nanobainitic microstructure characteristics markedly differ from those of the conventional lower bainite microstructure typically formed at a temperature regime of $200-350{ }^{\circ} \mathrm{C}$ in steels having a carbon content of $>0.8 \mathrm{wt} \%$ with relatively lower alloying elements compared with nanobainitic steels. The lower bainite microstructure is characterized by a plate-like bainitic ferrite morphology frequently containing very fine transition carbide precipitates largely having a common crystallographic orientation [9]. By contrast, bainitic ferrite in nanobainitic steel has a lath morphology containing few transition carbides formed through an autotempering phenomenon during the prolonged isothermal treatment. The extent of carbide formation is significantly lower than that in lower bainitic ferrite due to the presence of Si in the nanobainitic steel composition [10]. 
Some aspects of nanobainitic steels have been rather thoroughly studied, e.g., the variant selection mechanism [8, 11-12] and the carbon partitioning using an in situ neutron diffraction [11, 13, 14]. This unique microstructure also potentially enables the characterization of the orientation relationship and the interface character (i.e. habit plane) between bainitic ferrite and retained austenite because these crystallographic characteristics, to a large extent, control the plasticity of steel. For example, slip transfer across the interface appears to be easier when the adjacent phases possess an orientation relationship close to K-S $[15,16]$. Furthermore, it is reasonable to expect that the ease of dislocation transfer across the interface might be controlled by the character of the habit plane.

Recent reports have also revealed that the phase transformation temperature might have a strong effect on the variant selection, size and microstructural arrangement of bainite laths [2, 8, 11, 12]. Lowering the transformation temperature enhances the phase transformation driving force, which leads to more frequent nucleation of ferrite variants (i.e. weakening the variant selection). Furthermore, it promotes self-accommodation between ferritic laths because of increasing strength in the austenite matrix. Both these aspects ultimately limit the bainitic lath growth resulting in refinement of the microstructure $[1,2,8,17]$. Nevertheless, the effect of transformation temperature on the orientation relationship and the interface character (e.g., habit plane) has to date received only limited attention. The current study aims to further elucidate these issues in the relatively low temperature regime based on observations in an advanced nanobainitic steel.

As for grain boundaries, five independent crystallographic parameters are required to characterize the phase transformation interfaces (i.e., habit plane). They consist of three parameters specifying the lattice misorientation across adjacent retained austenite and bainitic ferrite, and two parameters defining the habit plane orientation/s [18]. The former can be potentially measured using conventional electron backscatter diffraction (EBSD) technique, while the latter requires threedimensional (3-D) measurements using transmission electron microscopy (TEM) or serial sectioning in conjunction with EBSD. TEM was used extensively in both martensite and bainite microstructures to examine the austenite habit plane $[19,20]$, though the results were not consistent, probably because of the limited number of interfaces examined in TEM.

3-D techniques have mostly been employed to measure the grain boundary distribution in single-phase polycrystalline materials with a grain size of more than $2 \mu \mathrm{m}$ [21-23]. There were also some attempts to measure the orientation and morphology of coarse martensite using 3-D EBSD, though this was restricted to only a few crystals [24-26]. The presence of nano-scale constituents (i.e. 
50-200 $\mathrm{nm}$ ) in the nanobainitic steel microstructure restricts the use of 3D-EBSD due to its limited spatial resolution of $\sim 40 \mathrm{~nm}$. New advances in interface/boundary characterization led to the development of a novel approach to statistically measure all five independent interface parameters using the conventional EBSD orientation mapping. The five-parameter approach, which is described in detail elsewhere [18], was employed for a wide range of single-phase materials such as ceramics [2729] and metals [30-32].

One of the objectives of the current work is to further develop the five-parameter analysis approach to characterise the habit plane/interface distribution in a two-phase microstructure. To overcome the spatial resolution of the conventional EBSD technique, the relatively new orientation mapping technique, viz. precession electron diffraction (PED) in the TEM, was employed to carry out orientation and phase mapping with high resolution. This technique has a spatial resolution of $\sim 2 \mathrm{~nm}$, which makes it possible to map all constituents present in the nanobainitic microstructure accurately.

\section{Experimental procedure}

Steel with a composition of $0.79 \mathrm{C}-1.5 \mathrm{Si}-1.98 \mathrm{Mn}-0.98 \mathrm{Cr}-0.24 \mathrm{Mo}-1.06 \mathrm{Al}-1.58 \mathrm{Co}$ (wt.\%) was used in the current study. The presence of high fractions of alloying elements in the steel resulted in high hardenability and a relatively low bainitic transformation temperature regime. The starting bainite (Bs) and martensite (Ms) phase transformation temperatures were 385 and $155^{\circ} \mathrm{C}$, respectively [33]. The specimens were initially reheated to $1100^{\circ} \mathrm{C}$ in a muffle furnace and held for 30 min, obtaining an average austenite grain size of $\sim 60 \mu \mathrm{m}$. The samples were then placed in a salt bath furnace at different bainitic transformation temperatures ranging from $200{ }^{\circ} \mathrm{C}$ to $350{ }^{\circ} \mathrm{C}$ at $50{ }^{\circ} \mathrm{C}$ intervals. The sample was held isothermally at each temperature so that the bainitic phase transformation went to completion. The isothermal holding times were 1 day, 2 days, 5 days and 10 days for isothermal holding temperatures of $350{ }^{\circ} \mathrm{C}, 300{ }^{\circ} \mathrm{C}, 250{ }^{\circ} \mathrm{C}$ and $200{ }^{\circ} \mathrm{C}$, respectively.

Thin foil samples for transmission electron microscopy (TEM) were initially prepared using $3 \mathrm{~mm}$ diameter discs mechanically ground to $\sim 0.07 \mathrm{~mm}$ thickness. They were then twin-jet electropolished using a solution containing $5 \%$ perchloric acid and $95 \%$ methanol at a temperature of $25{ }^{\circ} \mathrm{C}$ and a voltage of $50 \mathrm{~V}$. The TEM examination was conducted using JEOL JEM 2100F and Philips CM20 microscopes operated at $200 \mathrm{kV}$. The dislocation density of the bainitic ferrite was calculated as $\Lambda=2 N / L t$, where $N$ is the number of intersections with dislocations made by random lines with length $L$ and $t$ is the foil thickness [34]. Four to five of the bright and dark field images at different tilts and 
magnification of 100,000 times were used. The foil thickness, $t$, was determined from intensity oscillations in the two-beam convergent beam electron diffraction patterns [35].

Samples for electron backscatter diffraction (EBSD) were prepared by standard mechanical polishing, finished with a colloidal silica slurry polish. EBSD measurements were carried out using a FEGSEM Quanta 3D FEI scanning electron microscope operated at $20 \mathrm{kV}$. The instrument was equipped with a fully automated EBSD device attachment. Data acquisition and post processing were performed using the TexSEM Laboratories, Inc. software (TSL). The maps were acquired using a spatial step size of $0.15 \mu \mathrm{m}$ on a hexagonal grid. The total mapped area covered approximately $245 \times 255 \mu^{2}$, containing more than 20 prior austenite grains. The average confidence index generally varied between 0.45-0.55, depending on the isothermal holding temperature. All EBSD maps were first subjected to a grain dilation clean up function to eliminate ambiguous data. A single orientation was then assigned to a given grain by averaging all orientation data belonging to that grain.

The recently introduced NanoMEGAS ASTAR system [36] was employed for automated orientation and phase mapping of TEM foils. The data acquisition was performed using a Digistar device, attached to a JEM 2100F transmission electron microscope. This device performs scanning and simultaneous precession of the focused primary electron beam. The obtained nanobeam spot (disc) diffraction patterns are recorded by an external fast optical camera and indexed off-line using crosscorrelation with a pre-calculated set of templates with an angular precision of about $1^{\circ}[36]$. The crystal orientation maps are then constructed. The JEM 2100F microscope was operated at $200 \mathrm{kV}$ in a nanobeam mode using the condenser aperture of $10 \mu \mathrm{m}$, nominal spot size of $1.6 \mathrm{~nm}$, step size of $5 \mathrm{~nm}$ and the beam precession angle of $0.7^{\circ}$. The obtained orientation map data were also exported to both the EBSD HKL Technology/Oxford Instruments Channel 5 and TSL OIM ${ }^{\mathrm{TM}}$ software for further postprocessing and visualization.

The orientation maps were initially subjected to cleaning procedures, which were described in detail elsewhere [37]. Given the presence of two phases (i.e. bainitic ferrite and retained austenite) in the microstructures, the boundaries/interfaces were classified into three categories: (i) bainitic ferritebainitic ferrite interface, resulting from the impingement of two distinct bainitic lath orientations, (ii) bainitic ferrite-retained austenite interface and iii) retained austenite-retained austenite interface, representing the prior austenite grain boundaries. These data were treated separately to measure the interface character distribution formed through low temperature bainite transformation using the fiveparameter characterization approach [18]. In total, there were $~ 27,500$ bainitic ferrite-retained austenite 
traces, which were used to analyse the habit plane character distribution for both bainitic ferrite and retained austenite.

The samples for X-ray diffraction (XRD) measurements were further subjected to a severe chemical solution treatment containing $80 \%$ hydrogen peroxide, $5 \%$ hydrofluoric acid and $15 \%$ water, after the mechanical polishing. The chemical treatment was performed to remove the surface, which might have partially undergone austenite to martensite transformation during the sample preparation. The XRD was conducted using a Philips PW 1130 diffractometer with graphite monochromated $\mathrm{CuK}_{\alpha}$ radiation at $40 \mathrm{kV}$ and $30 \mathrm{~mA}$ in the $2 \theta$ range $40-100^{\circ}$. The volume fraction of retained austenite was measured using a direct comparison approach, comparing the integrated intensities of $(200)_{\gamma},(200)_{\alpha},(220)_{\gamma}$ and $(220)_{\alpha}$ reflections.

\section{Results and Discussion}

\subsection{Microstructures obtained from different isothermal temperatures}

A bainitic microstructure was formed at all isothermal holding temperatures, ranging from $200{ }^{\circ} \mathrm{C}$ to $350{ }^{\circ} \mathrm{C}$. The microstructures consisted of bainitic ferrite laths with high dislocation density and retained austenite. The isothermal holding temperature had a strong effect on the characteristics of the final microstructure (Table 1). The volume fraction of retained austenite decreased from $53 \pm 1 \%$ to $21 \pm 2 \%$ as the isothermal holding temperature decreased from $350{ }^{\circ} \mathrm{C}$ to $200{ }^{\circ} \mathrm{C}$ (Table 1). This was expected as the $\mathrm{T}_{0}{ }^{\prime}$ has a negative slope, resulting in a smaller retained austenite volume fraction with a decrease in the isothermal temperature. The $\mathrm{T}_{0}{ }^{\prime}$ is a temperature at which the free energy of ferrite and adjacent austenite are the same, taking into account the stored energy of bainitic ferrite due to the displacive mechanism of transformation [38].

The EBSD results showed that each prior austenite grain was divided into several packets consisting of one or more blocks (Figs. 1 and 2). Each block contained very fine laths and retained austenite, which can only be resolved through TEM examination due to their small size (Figs. 3 and 4). A decrease in the phase transformation temperature led to a significant refinement of all microstructure constituents (i.e. packet, block, lath and retained austenite, Figures 1-4 and Table 1). This resulted in a sharp increase in the hardness from $420 \pm 6 \mathrm{Hv}_{20 \mathrm{kgf}}$ at $350{ }^{\circ} \mathrm{C}$ to $648 \pm 7 \mathrm{Hv}_{20 \mathrm{kgf}}$ at $200{ }^{\circ} \mathrm{C}$.

The microstructure predominantly consisted of nanosized bainitic laths with high dislocation density surrounded by fine retained austenite films at the phase transformation temperatures of $200{ }^{\circ} \mathrm{C}$ and $250{ }^{\circ} \mathrm{C}$ (Fig. 3a). The thickness of bainitic laths was $\sim 60 \pm 10 \mathrm{~nm}$ and $\sim 80 \pm 20 \mathrm{~nm}$ at temperatures 
of $200{ }^{\circ} \mathrm{C}$ and $250{ }^{\circ} \mathrm{C}$, respectively. The average dislocation density of bainitic laths was measured as $\sim 4.7 \times 10^{15} \mathrm{~m}^{-2}$ for $200{ }^{\circ} \mathrm{C}$ and $\sim 3.65 \times 10^{15} \mathrm{~m}^{-2}$ for $250^{\circ} \mathrm{C}$ (Table 1). However, the bainitic ferrite laths had a relatively coarse thickness, ranging from 200 to $400 \mathrm{~nm}$, with a dislocation density of $\sim 2.9 \times 10^{15}$ $\mathrm{m}^{-2}$ and $\sim 2 \times 10^{15} \mathrm{~m}^{-2}$ at $300{ }^{\circ} \mathrm{C}$ and $350{ }^{\circ} \mathrm{C}$, respectively (Table 1 ).

It was demonstrated that the transformation temperature does not have a direct influence on the refinement of microstructure constituents (e.g. lath size). Nevertheless, reductions in the phase transformation temperature progressively increase both the austenite strength and phase transformation driving force. The latter promotes more frequent nucleation of bainitic ferrite variants, while the former enhances the self-accommodation between ferritic laths. These ultimately restrict the growth of the bainitic ferrite laths, which eventually results in the microstructure refinement $[1,2,8,17]$. The austenite strength appears to have the most dominant effect on the bainite microstructure refinement followed by the driving force. The yield strength of austenite can be estimated based on the phase transformation temperature and the chemical composition of the steel using equation 1 [17].

$\sigma=\left(1-0.26 \times 10^{-2} \mathrm{~T}_{\mathrm{r}}+0.47 \times 10^{-5} \mathrm{~T}_{\mathrm{r}}^{2}-0.326 \times 10^{-8} \mathrm{~T}_{\mathrm{r}}^{3}\right) \times 15.4\left(4.4+23 w_{C}+1.3 w_{S i}+0.24 w_{\mathrm{Cr}}+0.94 w_{\mathrm{Mo}}+0.32 w_{\mathrm{N}}\right)$

Equation 1

Where $\mathrm{T}_{\mathrm{r}}=\mathrm{T}-25, \mathrm{~T}$ represents the isothermal temperature in ${ }^{\circ} \mathrm{C}$ and $w$ is the concentration of alloying element in wt\%, defined by the subscript. The yield strength of austenite was estimated for the current steel at different phase transformation temperatures and listed in Table 1. The yield strength increased substantially from $\sim 209 \mathrm{MPa}$ to $\sim 260 \mathrm{MPa}$ for transformation temperatures of $350{ }^{\circ} \mathrm{C}$ and $200{ }^{\circ} \mathrm{C}$, respectively. This is consistent with the observation that the bainitic structure is significantly refined at decreased transformation temperature.

\subsection{Bainitic lath characteristics}

The phase transformation temperature resulted in a remarkable change in the bainitic lath characteristics. A close inspection of a single bainitic ferrite lath formed at an early stage of phase transformation at $200{ }^{\circ} \mathrm{C}$ revealed that it might be composed of small segments having similar orientations, as the corresponding diffraction pattern did not display extra orientation spots (Figs. 3c, d). In addition, some bainitic laths had a ragged morphology with small sidewise branches, having very close orientation to the main/primary lath (shown by arrows in Figure 3e). The retained austenite mostly appeared as a film with an average thickness of $\sim 30 \mathrm{~nm}$ for both conditions (Table 1). The nano-size twins were frequently observed within the retained austenite films in this temperature range 
(Fig. 3b). This can be explained by the need to accommodate the transformation strain, which is mainly related to the shear character of the bainite transformation. The presence of nano-scale twinning suggests that the stacking fault energy of austenite in this temperature regime is in the range of 20-50 $\mathrm{mJ} \mathrm{m} \mathrm{m}^{-2}$ to satisfy the mechanical twinning formation requirement [39].

At phase transformation temperature range of $300{ }^{\circ} \mathrm{C}$ and $350{ }^{\circ} \mathrm{C}$, two distinct bainite morphologies were observed. The first was bainite with a lamellar structure similar to the bainite morphology formed in the low temperature regime of $200-250{ }^{\circ} \mathrm{C}$ (Figs. 3 and 4). The second bainite morphology, frequently observed in the microstructure, contained two sets of bainitic laths with $\sim 30^{\circ}$ inclinations to each other under two-dimensional sectioning (Figs. $4 \mathrm{~b}$ and 2). Despite significant differences in their habit plane, these two sets of bainitic laths revealed a close crystallographic orientation with a local misorientation of less than $3^{\circ}$ (Fig. 2). Two distinct retained austenite morphologies (i.e. film and blocky) were present in the microstructure as a result of the special arrangement of bainitic laths (Figs. 4b-c). Both retained austenite morphologies locally displayed a similar orientation as they were retained from a given prior austenite grain. The retained austenite layers had an average thickness of $60 \pm 20 \mathrm{~nm}$ to $70 \pm 30 \mathrm{~nm}$ for $300{ }^{\circ} \mathrm{C}$ and $350{ }^{\circ} \mathrm{C}$, respectively (Table 1). The blocky retained austenite was generally less than $1 \mu \mathrm{m}$ in size.

The presence of sidewise (secondary) bainitic laths with a similar orientation to the primary bainitic lath is one of the most interesting aspects of the current bainitic phase transformation. This unique microstructural arrangement may have resulted from two main possible mechanisms: i) branching of a primary bainitic lath similar to what is observed in dendrite formation during solidification, and ii) sympathetic nucleation, where a new daughter phase nucleates at the interphase boundary of the pre-existing daughter phase (with an identical crystal structure) and the parent matrix [40].

The feasibility of dendrite-like branching was extensively studied during the growth of one phase into another in the solid state $[40,41]$. It was demonstrated that the crystallographic constraints associated with commonly observed orientation relationships between parent (e.g., austenite) and daughter (e.g., bainitic ferrite) phases largely prohibit the occurrence of dendrite-like branching during fcc-to-bcc phase transformation. In addition, the presence of the low misorientation boundary at the interface of the primary and secondary bainitic laths also dismisses the incidence of dendrite-like branching during the low temperature bainitic phase transformation in the current study.

Shewmon [42] demonstrated that sympathetic nucleation is likely to occur at the interphase 
boundaries having a relatively low energy with partially coherent facets between growth ledges, where substantial alloying element supersaturation is available. These interphase boundaries are immobile,

preventing them from overrunning embryos that nucleate through sympathetic nucleation. It was also demonstrated that sympathetic nucleation is energetically favorable to occur where it replaces the parent/daughter interphase by a lower energy daughter/daughter boundary. In addition, the nucleation of a similar orientation to the substrate daughter crystal further reduces the interfacial energy required to form a nucleus-substrate boundary [41]. Sympathetic nucleation mostly results in the formation of a small-angle grain boundary with respect to the pre-existing daughter phase (i.e. substrate). It is speculated that the presence of misfit dislocation/s associated with a partially coherent interphase boundary can lead to small changes in the orientation relationship between the parent matrix and sympathetically nucleated daughter phase, resulting in a low misorientation angle between sympathetic nuclei and the substrate [43].

The current observations, therefore, suggest that the sympathetic nucleation is, most likely, the main mechanism operating during the bainitic transformation in this temperature regime (i.e. $200{ }^{\circ} \mathrm{C}$ $350^{\circ} \mathrm{C}$ ). This type of nucleation was frequently observed in different alloying systems such as Fe-base [41] and Ti-base [44] alloys. Three different sympathetic nucleation configurations were reported, namely face-to-face, face-to-edge and edge-to-edge. The current results reveal that the transformation temperature (i.e. undercooling) significantly influences the sympathetic nucleation configurations, where the face-to-edge is the dominant nucleation mechanism in a temperature range of $300-350{ }^{\circ} \mathrm{C}$ (Figs. 2 and 4a), though both face-to-face and face-to-edge nucleation mechanisms are observed in the temperature range of $200-250{ }^{\circ} \mathrm{C}$ (Figs. 3c-e). The variation in the sympathetic nucleation configuration with the transformation temperature led to the change in the crystallographic arrangement of the final microstructure, as discussed below.

\subsection{Bainitic lath crystallographic arrangement}

The transformation temperature also altered significantly the crystallographic arrangement of bainitic ferrite laths (i.e. variant selection) formed in a given prior austenite grain. This can be clearly observed in the IPF-EBSD images, where each colour represents a crystallographic orientation normal to the plane of observation. Each orientation corresponds to a specific crystallographic variant (Figs. 1 and 2). At the lowest transformation temperature, i.e. $200{ }^{\circ} \mathrm{C}$, the crystallographic packets formed in a given parent austenite grain were relatively fine and consisted of two blocks with a distinct orientation having a similar habit plane (Fig. 1). This suggests that they belong to the same variant family. Based on TEM 
investigation, each block consisted of few laths with similar orientation separated by retained austenite films, as demonstrated schematically in Figure 5a. This crystallographic arrangement was frequently reported in lath martensite formed in low carbon steels [45]. As aforementioned, the formation of

secondary (sidewise branching) bainitic laths was regularly observed at high bainitic transformation temperatures, e.g., $350^{\circ} \mathrm{C}$. This led to the formation of a specific crystallographic arrangement, where a packet consisted of two blocks with a similar orientation, having different habit planes (Fig. 5b). This crystallographic configuration was also reported in the upper bainite formed in the heat-affected zone of a HSLA steel [46]. In general, the microstructure became much coarser with increasing transformation temperature, leading to the formation of fewer crystallographic variants. In other words, the variant selection became stronger with increasing transformation temperature.

The plastic strain is associated with the shear character of the transformation is evident from the presence of a high dislocation density in the bainitic laths (Table 1) and the formation of mechanical twinning in the retained austenite (Fig. 1b). In general, the formation of a preferred variant is associated with minimization of the prior austenite boundary energy and the strain energy related to the bainitic ferrite nucleation [1]. As discussed earlier, the transformation driving force is relatively small at the high transformation temperature (e.g. $350{ }^{\circ} \mathrm{C}$ ), leading to the nucleation of a specific variant that requires low activation energy. With decreasing transformation temperature (e.g., down to $200{ }^{\circ} \mathrm{C}$ ), the difference in the nucleation activation energy between variants is reduced. This potentially fulfills the condition for the nucleation of multiple variants (i.e. weakening the variant selection). As aforementioned, the prior austenite strength increases as the temperature decreases, leading to the formation of diverse crystallographic variants that tend to collectively accommodate the strain induced in the austenite during phase transformation [8]. Therefore, the observed difference in the variant selection with the phase transformation temperature might partly be associated with how easily the plastic strain induced in the parent austenite during phase transformation is accommodated.

\subsection{Orientation relationship}

Based on the parallelism of crystallographic planes and directions, the parent austenite and bainitic ferrite orientation relationship can be theoretically defined through five main models, namely Bain, Kurdjumov-Sachs (K-S), Greninger-Troiano (G-T) Pitsch and Nishiyama-Wassermann (N-W) (Table 2). The possible transformed product (i.e. bainitic lath) orientation/s can be, therefore, determined from a given parent austenite through the theoretical ORs. The predicted product orientations are very close for most ORs except Bain, which is hardly observed in practice. The G-T is between the K-S and N-W, 
which are separated by only $5.26^{\circ}$. It is worth mentioning that the transformed products mostly maintain the lattice invariant line rather than the parallel crystallographic planes and directions relationship. In other words, the theoretical ORs cannot be exactly fulfilled in practice, though the orientation relationship varies between the K-S and N-W depending on the difference between the lattice parameters of the parent austenite and transformed product [47]. This is clearly observed in Figure 6, where the austenite-bainitic ferrite locally revealed different orientation relationships, varying between the K-S and N-W ORs.

The orientation relationship between bainitic ferrite and parent austenite was measured for all the isothermal transformation temperatures using a recently developed clustering approach [48]. This method deduces the closest orientation relationship from a set of daughter (i.e. bainitic ferrite) variants formed in a given parent austenite grain. All possible parent austenite orientations are first deduced for each daughter (i.e. bainitic ferrite) orientation for a specific ideal orientation relationship. Each calculated parent austenite is compared with the ones deduced from other daughter variants. The orientation clusters are then constructed through the selection of potential parent austenite orientations of all other daughter variants by a minimum misorientation criterion. Finally, the summation of minimum misorientation angles (SMMA) of the clusters among all orientation relationships is considered as an objective function for identifying the correct (or most likely) orientation relationship. The phase transformation temperature had a significant effect on the closest orientation relationship between the parent austenite and bainitic ferrite (Fig. 7). At $350{ }^{\circ} \mathrm{C}$, the average of SMMA for 20 prior austenite grains was the lowest for the N-W OR among all ideal ORs, suggesting that this is, on average, the closest orientation relationship between bainitic ferrite and retained austenite at this phase transformation temperature. Interestingly, it gradually changed with the transformation temperature so that the K-S OR became the closest orientation relationship, i.e. having the least SMMA, at $200{ }^{\circ} \mathrm{C}$ (Fig. 7). This requires further investigation to understand how the transformation temperature influences the orientation relationship between the parent and daughter phase.

\subsection{Characteristics of the interfaces formed during bainitic transformation}

\subsubsection{Misorientation angle distribution}

The microstructure consisted of three types of interfaces, due to the presence of two distinct phases (i.e. bainitic ferrite and retained austenite), which were separated using EBSD maps. The misorientation angle distributions of interfaces with the highest statistical significance (i.e. retained austenite/bainitic 
ferrite and bainitic ferrite/bainitic ferrite) are presented in Figures 8 and 9. It appeared that the phase transformation temperature had a significant effect on the misorientation angle distribution of both types of interfaces. In general, the misorientation angle for the retained austenite/bainitic ferrite interfaces was in the range of $41^{\circ}$ to $47^{\circ}$ (Fig. 8). At the highest temperature, $350{ }^{\circ} \mathrm{C}$, the misorientation angle peak was close to $45^{\circ}$, which is close to the misorientation angle expected for the ideal N-W OR (Table 2). As the temperature decreased, the peak of the misorientation angle distribution progressively moved towards a lower misorientation angle. This suggests that the OR gradually changed from the NW towards the K-S OR, which is consistent with the results obtained from the clustering approach using the orientations of the bainitic laths (Fig. 7).

The misorientation angle distribution of bainitic ferrite/bainitic ferrite interfaces revealed two distinct populations in the range of $10-23^{\circ}$ and $47-62.8^{\circ}$ (Fig. 9). This is consistent with the theoretical misorientation angles that result from the impingement of two distinct bainitic ferrite variants. For the $\mathrm{K}-\mathrm{S}$ OR, the theoretical misorientation angles are 10.5, 14.9, 20.6, 21.1, 47.1, 49.5, 50.5, 51.7, 57.2, and $60^{\circ}$ [45]. In case of the N-W OR, they are 13.8, 19.5, 50.1, 53.7, and $60^{\circ}$ [49]. From the above figure, it is clear that the phase transformation temperature significantly influenced the distribution. The low misorientation angle population had a single peak at $\sim 15^{\circ}$ at $200{ }^{\circ} \mathrm{C}$ and split into two distinct peaks at $\sim 14^{\circ}$ and $\sim 20^{\circ}$ at $250^{\circ} \mathrm{C}$ and above. For the high angle population, three distinct peaks appeared (i.e. at $\sim 52^{\circ}, 57^{\circ}$ and $60^{\circ}$ ) at all transformation temperatures. However, their intensities gradually changed with temperature, specifically for the peak located at $57^{\circ}$ whose population decreased from $\sim 11 \%$ at $200{ }^{\circ} \mathrm{C}$ to $\sim 4 \%$ at $350{ }^{\circ} \mathrm{C}$ (Fig. 9). This trend was in good agreement with the change in the orientation relationship from the $\mathrm{N}-\mathrm{W}$ at $350{ }^{\circ} \mathrm{C}$ towards the $\mathrm{K}-\mathrm{S}$ at $200{ }^{\circ} \mathrm{C}$ discussed above (see Figs. 7 and 8).

It is worth mentioning that the interfaces obtained from the conventional EBSD technique can only represent these microstructures qualitatively, as the size of microstructure constituents (i.e. bainitic ferrite and retained austenite) was in the range of (or smaller than) the spatial resolution of the EBSD technique (i.e. $\sim 40 \mathrm{~nm}$ ). Therefore, some parts of the microstructure were not indexed appropriately. As a result, most of the bainitic ferrite/bainitic ferrite interfaces were over-represented in the EBSD maps, though they must be mostly separated by fine retained austenite films as shown in TEM images (Figs. 3a and 4). In other words, the bainitic ferrite/retained austenite interfaces were not resolved and replaced by bainitic ferrite/bainitic ferrite interfaces. 
The NanoMEGAS ASTAR approach overcomes this lack of spatial resolution and enables the retained austenite and bainitic lath phases to be measured. Similar to the EBSD result, the misorientation angle distribution of bainitic ferrite/retained austenite interfaces showed that the overall misorientation angle shifted from $46^{\circ}$ towards $42^{\circ}$ with a decrease in the phase transformation temperature (Fig. 10). Strictly speaking, the orientation relationship gradually deviated from the N-W towards the K-S as the phase transformation was reduced from $350{ }^{\circ} \mathrm{C}$ to $200{ }^{\circ} \mathrm{C}$.

\subsubsection{Three-parameter Rodrigues-Frank space of bainitic ferrite-retained austenite interfaces}

The misorientation angle distribution discussed above only represents one crystallographic parameter of the retained austenite/bainitic ferrite interface. Figure 11 shows the retained austenite/bainitic lath interface data plotted in terms of the Rodrigues-Frank (R-F) vector space, which resolves three crystallographic parameters (i.e. misorientation angle/axis or three Euler angles). In the R-F vector space, the lattice misorientation is a vector, $\mathrm{R}=\mathrm{n}_{\mathrm{i}} \tan (\omega / 2)$, where $\mathrm{n}_{\mathrm{i}}(\mathrm{i}=1,2,3)$ are the unit vector components representing the misorientation axis, $\omega$ is the misorientation angle and $\mathrm{R}$ has three components $R_{1}, R_{2}$ and $R_{3}$. Here, the $R-F$ space fundamental zone for the retained austenite/bainitic ferrite interfaces (both sides having cubic structure) appears as two adjoining truncated pyramids. In other words, the fundamental zone for two-phase microstructure is twice the size of that for the singlephase microstructure. The 100, 110 and 111 axes lie along edges of the fundamental zone. The R-F space is often sectioned parallel to the 100-110 plane for graphical representation (Fig. 11). There were strong peaks slightly deviated from the position of the Bain orientation relationship having $\mathrm{R}=(0, \sqrt{2}-1$, $0)$ and $(\sqrt{ } 2-1,0,0)$, which correspond to $45^{\circ} /[100]$ in the misorientation angle-axis pair convention. This suggests that the Bain OR was not present in the distribution and these peaks were mostly related to other orientation relationships, namely K-S, N-W, G-P and Pitsch (see Fig. 11 and Table 2). This is consistent with the observation made for the orientation relationship in a Gibeon meteorite, where all the main orientation relationships were satisfied except the Bain OR [50]. By contrast, the Bain OR was seen in the $\mathrm{R}-\mathrm{F}$ space of $\mathrm{Nb} / \mathrm{Cu}$ multilayer interfaces produced through the accumulative rollbonding technique. This unique observation could be due to the introduction of specific texture through the rolling, which ultimately enhances the Bain OR [51]. Considering the R-F space (i.e. the misorientation angle/axis pairs), there is a change in the orientation relationship along the interfaces of bainitic lath and retained austenite. The spread in OR was also reported by others, where it was suggested that the interface energy minimization is defined by the parallel plane matching criteria rather than the direction parallelism $[50,52]$. Therefore, it is necessary to determine all five 
crystallographic parameters (i.e. misorientation angle/axis pairs along with the habit plane) of bainitic lath and retained austenite interfaces.

\subsubsection{Five-parameter crystallographic characteristics of retained austenite/bainitic ferrite habit planes}

Figure 12 shows the distribution of relative areas of interface planes for both the retained austenite and bainitic ferrite laths, plotted in the stereographic projection in the crystal reference frame ignoring misorientations, based on orientation maps acquired with the NanoMegas PED system. The distribution of retained austenite habit planes revealed an anisotropy with a maximum at the (111) position having 1.7 MRD (i.e. $70 \%$ greater than random distribution), spreading towards (554) plane (Fig. 12a). The minimum was centred at the (001) position having 0.5 MRD. In the case of bainitic ferrite lath habit planes, there was a wide peak spreading from the (101) through the (535) position with 1.5 MRD. The minimum was at the (001) orientation having 0.25 MRD (Fig. 12b).

The retained austenite and bainitic ferrite lath habit planes were analysed further using all five crystallographic parameters (Fig. 13). Here, the boundary segments were partitioned into two different sets (i.e. K-S OR and N-W OR) depending on which OR was best satisfied. The habit planes distributions were slightly different for the K-S and N-W ORs. In addition, the relative area of habit planes was relatively higher for the N-W OR compared with the K-S OR for both retained austenite and bainitic ferrite laths. For the case of the N-W OR, the distributions were qualitatively similar to what was observed for all the interphase interfaces ignoring the misorientation (Figs. 12 and 13b,d). For the K-S OR, the retained austenite habit planes distribution displayed the maximum (i.e. 1.8 MRD) at the position of (111) and a relatively weaker peak ( 1.3 MRD) centred at (494). The bainitic ferrite lath habit plane distribution was much more spread, showing two main peaks at (101) and (535) positions (Figs. 13a,c).

The maxima at (101) and (111) for bainitic ferrite lath and retained austenite, respectively, correspond well with the crystallographic planes associated with both the K-S and N-W ORs (Fig. 12 and Table 2). They are also consistent with the minimum energy positions calculated for bcc and fcc crystal structures, respectively, using the first nearest broken bond model [51]. However, the spread observed in both the retained austenite and bainitic lath habit planes distribution neither follows the crystallographic constraints associated with the main OR models (Table 2) nor fulfils the minimum energy requirements. Indeed, some of the interphase boundaries significantly deviated from the main ORs, though their misorientation angle/axis pairs appear close to either the K-S or N-W OR. This could 
be due to the irrational nature of interfaces formed through the bainitic (i.e. shear) transformation to maintain an invariant-line located in the interface of parent and daughter phases [53], the tetragonality of the body-centred bainitic lath in high-carbon high-alloyed steel [54] and the presence of the high dislocation density in the bainitic microstructure (Table 1).

The habit planes reported by others for the austenite and bainitic laths, along with martensitic laths, are summarized in Figure 12c. It should be emphasised that the habit planes may be altered by the phase transformation mechanism. For example, the habit plane of austenite was measured close to (254) [19] for a lower bainite microstructure formed in a Fe-1.11C-7.9Cr (in wt\%), though it became close to (494) for the lath martensite formed for the same composition [19]. The austenite habit plane in martensitic transformation was mostly measured as (111) [20], (554) [20] and (254) [19] using a TEM approach. The corresponding martensitic lath habit planes were more scattered, and were reported as (110) [55-58], near (110) [59], (541) [60], (321) [61] and (331) [58]. Interestingly, most of these planes are present in the distributions measured for both retained austenite and bainitic ferrite habit planes using the current five-parameter interface analysis approach. The present results reveal the complexity of the habit planes formed through the low temperature bainitic transformation. The misorientation angle/axis pairs are not, indeed, a sufficient criterion to fully define the interface characteristics, as the habit planes may differ significantly from what is expected from the crystallographic constrains associated with the main ORs and/or the minimum energy interface requirement (i.e. $\left.(111)_{\gamma} / /(110)_{\alpha}\right)$.

\section{Conclusions}

The current investigation examined the crystallographic characteristics of nano-scale bainite formed at relatively low isothermal transformation temperatures (i.e. $200-350{ }^{\circ} \mathrm{C}$ ) in a $0.79 \mathrm{C}-1.5 \mathrm{Si}-1.98 \mathrm{Mn}$ $0.98 \mathrm{Cr}-0.24 \mathrm{Mo}-1.06 \mathrm{Al}-1.58 \mathrm{Co}$ (in wt.\%) steel. The phase transformation temperature had a significant impact on the resultant microstructures, generally comprising the bainitic ferrite laths and retained austenite. The observed microstructural changes include:

1) A decrease in the transformation temperature led to a progressive microstructure refinement to such extent that nanostructured bainite was obtained below $250{ }^{\circ} \mathrm{C}$.

2) Two distinct types of bainite crystallographic arrangements were observed depending on the temperature. The bainite packets formed at $200-250{ }^{\circ} \mathrm{C}$ typically contained one or more blocks (i.e. bainitic ferrite laths and retained austenite lamellae) having different orientations and a common habit plane. Some of the bainitic laths comprised small segments having similar 
orientations, whereas others exhibited a ragged morphology with fine protrusions, which implies face-to-face and face-to-edge sympathetic nucleation, respectively.

3) The face-to-edge sympathetic nucleation mechanism seemed to be prevalent at $300-350{ }^{\circ} \mathrm{C}$, since the bainite packets largely contained two sets of bainitic ferrite laths having similar orientations and being inclined to each other (i.e. having different habit planes).

4) All rational orientation relationship models, ranging from $\mathrm{K}-\mathrm{S}$ through to $\mathrm{N}-\mathrm{W}$, were identified within the current transformation temperature range. At $350{ }^{\circ} \mathrm{C}$, the $\mathrm{N}-\mathrm{W}$ OR was prevalent and gradually changed towards K-S OR, which dominated at $200{ }^{\circ} \mathrm{C}$.

5) The habit plane distributions for both bainitic ferrite and retained austenite were statistically measured. They were generally irrational and displayed a significant anisotropy. The bainitic ferrite plane distribution showed a wide peak spreading from the (101) towards the (535) plane. The retained austenite exhibited a maximum at the (111) orientation, extending towards the (554) plane.

\section{Acknowledgements:}

This research was supported by grants through the Australian Research Council including an ARC Federation Fellowship (P.D.H.). This work was carried out with the support of the Deakin Advanced Characterization Facility. A.D.R. acknowledges support from the US National Science Foundation under DMREF grant number 1435544. G.S.R. acknowledges support from the US National Science Foundation under grant DMR 1628994.

\section{References}

[1] T. Furuhara, H. Kawata, S. Morito, T. Maki, Crystallography of upper bainite in Fe-Ni-C alloys, Mater. Sci. Eng., A 431(1-2) (2006) 228-236.

[2] N. Takayama, G. Miyamoto, T. Furuhara, Effects of transformation temperature on variant pairing of bainitic ferrite in low carbon steel, Acta Mater. 60(5) (2012) 2387-2396.

[3] P. Brozzo, G. Buzzichelli, A. Mascanzoni, M. Mirabile, Microstructure and cleavage resistance of low-carbon bainitic steels, Metal Science 11(4) (1977) 123-130.

[4] B. Hutchinson, J. Komenda, G.S. Rohrer, H. Beladi, Heat affected zone microstructures and their influence on toughness in two microalloyed HSLA steels, Acta Mater. 97 (2015) 380-391.

[5] F.G. Caballero, H.K.D.H. Bhadeshia, K.J.A. Mawella, D.G. Jones, P. Brown, Design of novel high strength bainitic steels: Part 1, Mater. Sci. Technol. 17(5) (2001) 512-516.

[6] H.K.D.H. Bhadeshia, 52nd Hatfield Memorial Lecture Large chunks of very strong steel, Mater. Sci. Technol. 21(11) (2005) 1293-1302.

[7] C. Garcia-Mateo, F.G. Caballero, Ultra-high-strength Bainitic Steels, ISIJ Int. 45(11) (2005) 17361740.

[8] H. Beladi, Y. Adachi, I. Timokhina, P.D. Hodgson, Crystallographic analysis of nanobainitic steels, Scripta Mater. 60(6) (2009) 455-458. 
[9] H. Okamoto, M. Oka, Lower bainite with midrib in hypereutectoid steels, Metall Trans A. 17(7) (1986) 1113-1120.

[10] I.B. Timokhina, H. Beladi, X.Y. Xiong, Y. Adachi, P.D. Hodgson, Nanoscale microstructural characterization of a nanobainitic steel, Acta Mater. 59(14) (2011) 5511-5522.

[11] W. Gong, Y. Tomota, Y. Adachi, A.M. Paradowska, J.F. Kelleher, S.Y. Zhang, Effects of ausforming temperature on bainite transformation, microstructure and variant selection in nanobainite steel, Acta Mater. 61(11) (2013) 4142-4154.

[12] W. Gong, Y. Tomota, M.S. Koo, Y. Adachi, Effect of ausforming on nanobainite steel, Scripta Mater. 63(8) (2010) 819-822.

[13] H.J. Stone, M.J. Peet, H.K.D.H. Bhadeshia, P.J. Withers, S.S. Babu, E.D. Specht, Synchrotron Xray studies of austenite and bainitic ferrite, Proceedings of the Royal Society A: Mathematical, Physical and Engineering Science 464(2092) (2008) 1009.

[14] K. Rakha, H. Beladi, I. Timokhina, X. Xiong, S. Kabra, K.-D. Liss, P. Hodgson, On low temperature bainite transformation characteristics using in-situ neutron diffraction and atom probe tomography, Mater. Sci. Eng., A 589 (2014) 303-309.

[15] M.-C. Marinelli, A. El Bartali, J.W. Signorelli, P. Evrard, V. Aubin, I. Alvarez-Armas, S. Degallaix-Moreuil, Activated slip systems and microcrack path in LCF of a duplex stainless steel, Mater. Sci. Eng., A 509(1-2) (2009) 81-88.

[16] I. Serre, D. Salazar, J.B. Vogt, Atomic force microscopy investigation of surface relief in individual phases of deformed duplex stainless steel, Mater. Sci. Eng., A 492(1-2) (2008) 428-433.

[17] S.B. Singh, H.K.D.H. Bhadeshia, Estimation of bainite plate-thickness in low-alloy steels, Mater. Sci. Eng., A 245(1) (1998) 72-79.

[18] G. Rohrer, D. Saylor, B. El Dasher, B. Adams, A. Rollett, P. Wynblatt, The distribution of internal interfaces in polycrystals, Z. Metallk. 95(4) (2004) 197-214.

[19] G.R. Srinivasan, C.M. Wayman, Transmission electron microscope study of the bainite transformation in iron-chromium-carbon alloys, Acta Metall. 16(5) (1968) 609-620.

[20] T. Maki, Diffusionless transformations, high strength steels, modelling and advanced analytical techniques, Woodhead Publishing, 2012.

[21] H. Beladi, G. Rohrer, The relative grain boundary area and energy distributions in a ferritic steel determined from three-dimensional electron backscatter diffraction maps, Acta Mater. 61(4) (2013) 1404-1412.

[22] J. Li, S. Dillon, G. Rohrer, Relative grain boundary area and energy distributions in nickel, Acta Mater. 57(14) (2009) 4304-4311.

[23] S.J. Dillon, G.S. Rohrer, Characterization of the Grain-Boundary Character and Energy Distributions of Yttria Using Automated Serial Sectioning and EBSD in the FIB, J. Am. Ceram. Soc. 92(7) (2009) 1580-1585.

[24] D.J. Rowenhorst, A. Gupta, C.R. Feng, G. Spanos, 3D Crystallographic and morphological analysis of coarse martensite: Combining EBSD and serial sectioning, Scripta Mater. 55(1) (2006) 1116.

[25] S. Morito, Y. Adachi, T. Ohba, Morphology and Crystallography of Sub-Blocks in Ultra-Low Carbon Lath Martensite Steel, Materials Transactions 50(8) (2009) 1919-1923.

[26] S. Morito, Y. Edamatsu, K. Ichinotani, T. Ohba, T. Hayashi, Y. Adachi, T. Furuhara, G. Miyamoto, N. Takayama, Quantitative analysis of three-dimensional morphology of martensite packets and blocks in iron-carbon-manganese steels, J. Alloys Compd. 577, Supplement 1 (2013) S587-S592.

[27] D. Saylor, B. El Dasher, T. Sano, G. Rohrer, Distribution of Grain Boundaries in SrTiO3 as a Function of Five Macroscopic Parameters, J. Am. Ceram. Soc. 87(4) (2004) 670-676. 
[28] D. Saylor, B. Dasher, Y. Pang, H. Miller, P. Wynblatt, A. Rollett, G. Rohrer, Habits of grains in dense polycrystalline solids, J. Am. Ceram. Soc. 87(4) (2004) 724-726.

[29] D. Saylor, A. Morawiec, G. Rohrer, The relative free energies of grain boundaries in magnesia as a function of five macroscopic parameters, Acta Mater. 51(13) (2003) 3675-3686.

[30] D. Saylor, B. El Dasher, A. Rollett, G. Rohrer, Distribution of grain boundaries in aluminum as a function of five macroscopic parameters, Acta Mater. 52(12) (2004) 3649-3655.

[31] H. Beladi, G.S. Rohrer, The Distribution of Grain Boundary Planes in Interstitial Free Steel, Metallurgical and Materials Transactions A 44(1) (2013) 115-124.

[32] C.-S. Kim, Y. Hu, G.S. Rohrer, V. Randle, Five-parameter grain boundary distribution in grain boundary engineered brass, Scripta Mater. 52 (2005) 633-637.

[33] C. Garcia-Mateo, F.G. Caballero, H.K.D.H. Bhadeshia, Acceleration of low-temperature bainite, ISIJ Int. 43(11) (2003) 1821-1825.

[34] P. Hirsch, R. Nicholson, A. Howie, D. Pashley, M. Whelan, Electron microscopy of thin crystals, Butterworth, London, 1965.

[35] P. Kelly, A. Jostsons, R. Blake, J. Napier, The determination of foil thickness by scanning transmission electron microscopy, Phys. Status Solidi 31(2) (1975) 771-780.

[36] E.F. Rauch, J. Portillo, S. Nicolopoulos, D. Bultreys, S. Rouvimov, P. Moeck, Automated nanocrystal orientation and phase mapping in the transmission electron microscope on the basis of precession electron diffraction, Zeitschrift für Kristallographie International 225(2-3) (2010) 103-109.

[37] H. Beladi, G. Rohrer, A. Rollett, V. Tari, P. Hodgson, The distribution of intervariant crystallographic planes in a lath martensite using five macroscopic parameters, Acta Mater. 63 (2014) 86-98.

[38] F.G. Caballero, M.J. Santofimia, C. García-Mateo, J. Chao, C.G. de Andrés, Theoretical design and advanced microstructure in super high strength steels, Materials \& Design 30(6) (2009) 2077-2083. [39] L. Rémy, A. Pineau, Twinning and strain-induced f.c.c. $\rightarrow$ h.c.p. transformation on the mechanical properties of Co-Ni-Cr-Mo alloys, Materials Science and Engineering 26(1) (1976) 123-132.

[40] E.S.K. Menon, H. Aaronson, Overview no. 57 Morphology, crystallography and kinetics of sympathetic nucleation, Acta Metall. 35(3) (1987) 549-563.

[41] H. Aaronson, M. Plichta, G. Franti, K.C. Russell, Precipitation at interphase boundaries, Metall. Trans. A 9(3) (1978) 363-371.

[42] P. Shewmon, Interfacial stability in solid-solid transformations, Transactions of the Metallurgical Society of AIME 233 (1965) 736-748.

[43] H. Aaronson, G. Spanos, R. Masamura, R. Vardiman, D. Moon, E. Menon, M. Hall, Sympathetic nucleation: an overview, Mater. Sci. Eng., B 32(3) (1995) 107-123.

[44] C. Dube, Thesis, Carnegie Institute of Technology, Pittsburgh, 1948.

[45] H. Kitahara, R. Ueji, N. Tsuji, Y. Minamino, Crystallographic features of lath martensite in lowcarbon steel, Acta Mater. 54(5) (2006) 1279-1288.

[46] A. Lambert-Perlade, A.F. Gourgues, A. Pineau, Austenite to bainite phase transformation in the heat-affected zone of a high strength low alloy steel, Acta Mater. 52(8) (2004) 2337-2348.

[47] J. Christian, Simple geometry and crystallography applied to ferrous bainites, Metall. Trans. A 21(3) (1990) 799-803.

[48] V. Tari, A. Rollett, H. Beladi, Back calculation of parent austenite orientation using a clustering approach, J. Appl. Crystallogr. 46(1) (2013) 210-215.

[49] H. Kitahara, R. Ueji, M. Ueda, N. Tsuji, Y. Minamino, Crystallographic analysis of plate martensite in Fe-28.5 at.\% Ni by FE-SEM/EBSD, Mater. Charact. 54(4) (2005) 378-386. 
[50] Y. He, S. Godet, J.J. Jonas, Representation of misorientations in Rodrigues-Frank space: application to the Bain, Kurdjumov-Sachs, Nishiyama-Wassermann and Pitsch orientation relationships in the Gibeon meteorite, Acta Mater. 53(4) (2005) 1179-1190.

[51] S.-B. Lee, J. LeDonne, S. Lim, I. Beyerlein, A. Rollett, The heterophase interface character distribution of physical vapor-deposited and accumulative roll-bonded $\mathrm{Cu}-\mathrm{Nb}$ multilayer composites, Acta Mater. 60(4) (2012) 1747-1761.

[52] H. Bunge, W. Weiss, H. Klein, W. L, G. U, S. JR, Orientation relationship of Widmannstätten plates in an iron meteorite measured with high-energy synchrotron radiation, J. Appl. Crystallogr. 36 (2003) 137-140.

[53] H. Bhadeshia, Bainite in steels, The University Press, Cambridge, 2001.

[54] H. Bhadeshia, Carbon in cubic and tetragonal ferrite, Philos. Mag. 93(28-30) (2013) 3714-3725.

[55] P.M. Kelly, A. Jostsons, R.G. Blake, The orientation relationship between lath martensite and austenite in low carbon, low alloy steels, Acta Metallurgica et Materialia 38(6) (1990) 1075-1081.

[56] P.M. Kelly, The martensite transformation in steels with low stacking fault energy, Acta Metall. 13(6) (1965) 635-646.

[57] M. Biswas, I. Codd, An electron transmission study of iron-nitrogen martensite, J IRON STEEL INST 206(5) (1968) 494-497.

[58] G. Thomas, V. Rao, Proc Int Conf Martensite ICOMAT, Kiev, U.S.S.R., 1978.

[59] F. Duflos, R. Cantor, Overview 15 The microstructure and kinetics of martensite transformations in splat-quenched Fe and FeNi alloys-I. Pure Fe, Acta Metall. 30(2) (1982) 323-342.

[60] A. Van Gent, F.C. Van Doorn, E.J. Mittemeijer, Crystallography and tempering behavior of ironnitrogen martensite, Metall. Trans. A 16(8) (1985) 1371-1384.

[61] J. Chilton, C. Barton, G. Speich, Martensite transformation in low-carbon steels, J Iron Steel Inst 208(2) (1970) 184-193. 
Table 1: bainitic microstructure characteristics at different heat treatment conditions.

\begin{tabular}{|c|c|c|c|c|c|c|c|c|}
\hline $\begin{array}{c}\text { Temperature } \\
\left({ }^{\circ} \mathrm{C}\right)\end{array}$ & $\begin{array}{l}\text { Time } \\
\text { (day) }\end{array}$ & $\begin{array}{c}\text { Hardness } \\
\left(\mathrm{Hv}_{20 \mathrm{kgf}}\right)\end{array}$ & $\begin{array}{c}\text { BF thickness } \\
\text { (nm) }\end{array}$ & $\begin{array}{l}\text { Dislocation } \\
\text { density }\left(\mathrm{m}^{-2}\right)\end{array}$ & $\begin{array}{l}\mathrm{RA} \\
(\%)\end{array}$ & $\begin{array}{c}\text { RA film } \\
\text { thickness (nm) }\end{array}$ & RA morphology & $\begin{array}{l}\text { *Austenite yield } \\
\text { strength (MPa) }\end{array}$ \\
\hline 200 & 10 & $648 \pm 7$ & $60 \pm 10$ & $4.7 \times 10^{15}$ & $21 \pm 2$ & $30 \pm 5$ & Film & 260 \\
\hline 250 & 5 & $579 \pm 6$ & $80 \pm 20$ & $3.65 \times 10^{15}$ & $28 \pm 3$ & $30 \pm 10$ & Film & 239 \\
\hline 300 & 2 & $510 \pm 4$ & $118 \pm 40$ & $2.9 \times 10^{15}$ & $42 \pm 2$ & $60 \pm 20$ & Film and blocky & 222 \\
\hline 350 & 1 & $420 \pm 6$ & $300 \pm 100$ & $2 \times 10^{15}$ & $53 \pm 1$ & $70 \pm 30$ & Film and blocky & 209 \\
\hline
\end{tabular}

RA and BF represent retained austenite and bainitic ferrite, respectively.

* Austenite yield strength was estimated based on the steel composition and phase transformation temperature using equation 1 [17]. 
Table 2: ideal orientation relationships between bainitic ferrite $(\alpha)$ and parent austenite $(\gamma)$.

\begin{tabular}{|l|l|l|l|}
\hline Orientation Relationship & Parallelism & Minimum angle/axis & $\begin{array}{l}\text { Rodrigues-Frank } \\
\text { vector (R) }\end{array}$ \\
\hline Bain & $\begin{array}{l}\{100\}_{\gamma} \|\{100\}_{\alpha} \\
\left.\langle 100\rangle_{\gamma} \|<110\right\rangle_{\alpha}\end{array}$ & $45^{\circ} /<100>$ & $(0, \sqrt{2}-1,0)$ \\
\hline Kurdjumov-Sachs & $\begin{array}{l}\{111\}_{\gamma} \|\{110\}_{\alpha} \\
\left.<110\rangle_{\gamma} \|<111\right\rangle_{\alpha}\end{array}$ & $42.85^{\circ} /<0.9680 .1780 .178>$ & $(0.38,0.07,0.07)$ \\
\hline Greninger-Troiano & $\begin{array}{l}\{111\}_{\gamma} \|\{110\}_{\alpha} \\
\left.<123\rangle_{\gamma} \|<133\right\rangle_{\alpha}\end{array}$ & $44.23^{\circ} /<0.9730 .1890 .133>$ & $(0.395,0.077,0.054)$ \\
\hline Pitsch & $\begin{array}{l}\{100\}_{\gamma} \|\{110\}_{\alpha} \\
\left.<110\rangle_{\gamma} \|<111\right\rangle_{\alpha}\end{array}$ & $45.98^{\circ} /<0.080 .20 .98>$ & $(0.085, \sqrt{2}-1,0.035)$ \\
\hline Nishiyama-Wasserman & $\begin{array}{l}\{111\}_{\gamma} \|\{110\}_{\alpha} \\
\left.<112\rangle_{\gamma} \|<110\right\rangle_{\alpha}\end{array}$ & $45.98^{\circ} /<0.9760 .0830 .201>$ & $(\sqrt{2}-1,0.085,0.035)$ \\
\hline
\end{tabular}



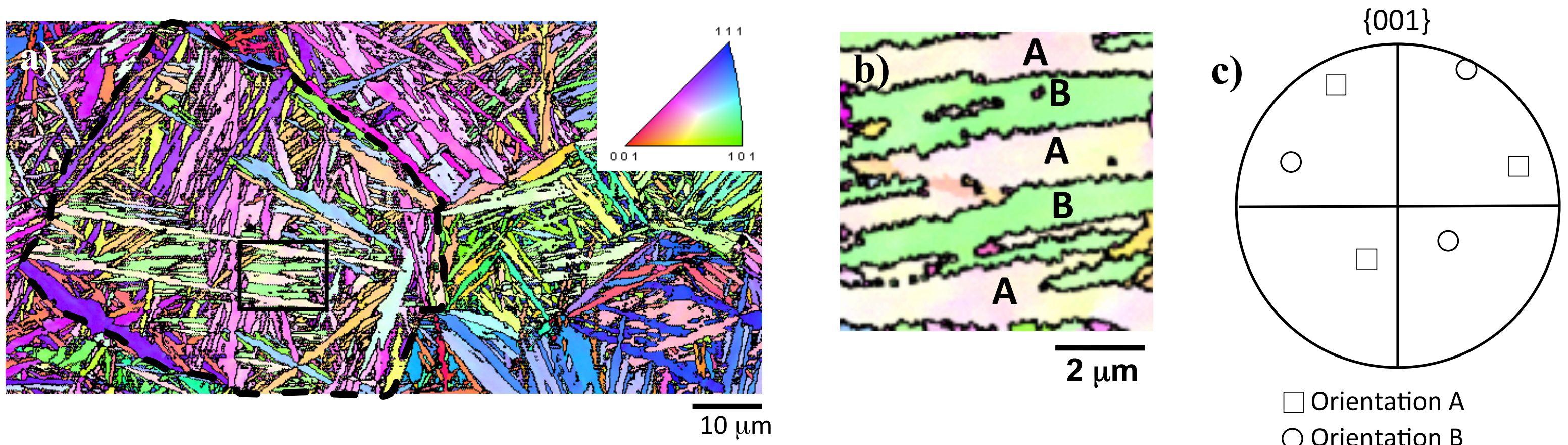

$\square$ Orientation A

Orientation B

Figure 1: a) IPF-EBD image of fully bainitic microstructure formed at $200^{\circ} \mathrm{C}$ isothermal temperature. Inset in (a) represents the color codes referred to normal direction. Dash lines in (a) delineated a prior austenite grain boundary. b) bainitic packet highlighted by a black line box in (a). A and B represent two distinct orientations/ blocks belong to a given packet. c) (001) pole figures of $A$ and $B$ orientations. 

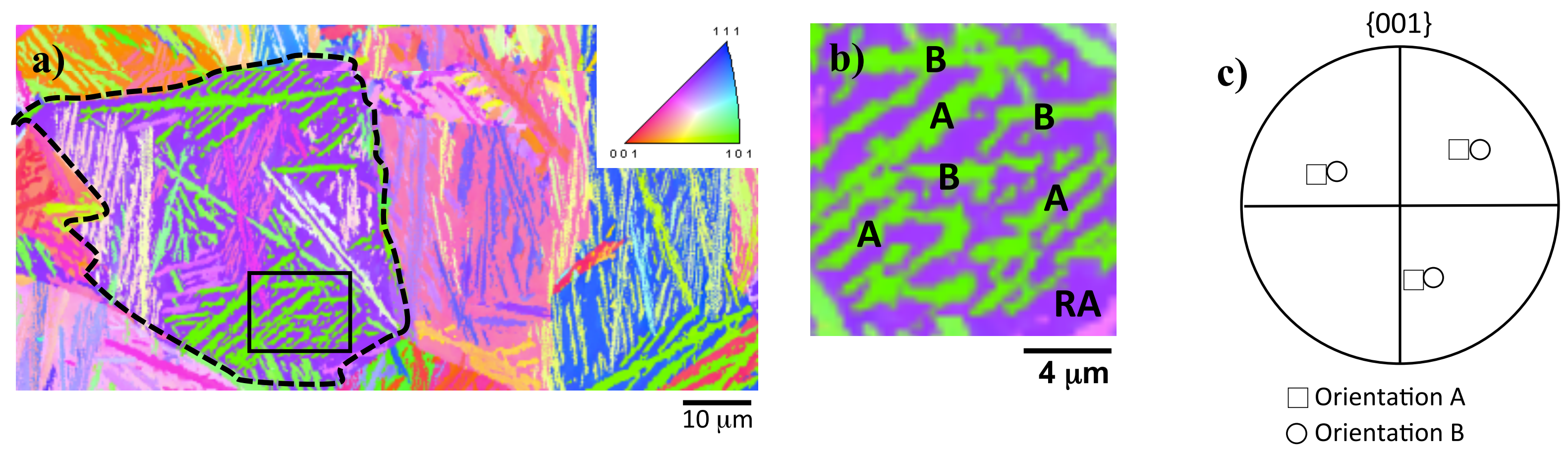

Figure 2: a) IPF-EBD image of fully bainitic microstructure formed at $350^{\circ} \mathrm{C}$ isothermal temperature. Inset in (a) represents the color codes referred to normal direction. Dash lines in (a) delineated a prior austenite grain boundary. b) bainitic packet highlighted by a black line box in (a). RA is retained austenite. A and B represent two distinct orientations/blocks belong to a given packet. c) (001) pole figures of $A$ and $B$ orientations. 

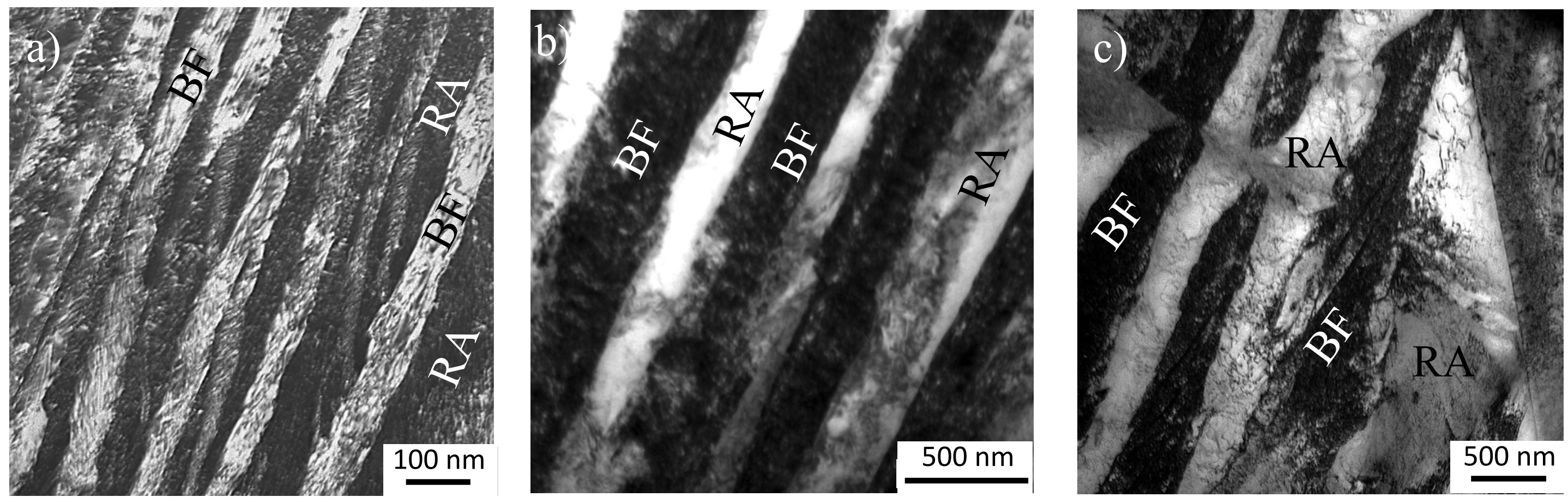

Figure 4: TEM images of bainitic lath formed at different bainitic transformation temperatures: a) $300^{\circ} \mathrm{C}$ for 3 days and $b-c) 350^{\circ} \mathrm{C}$ for 1 day. $\mathrm{BF}$ and RA are the bainitic ferrite and retained austenite. 
a)

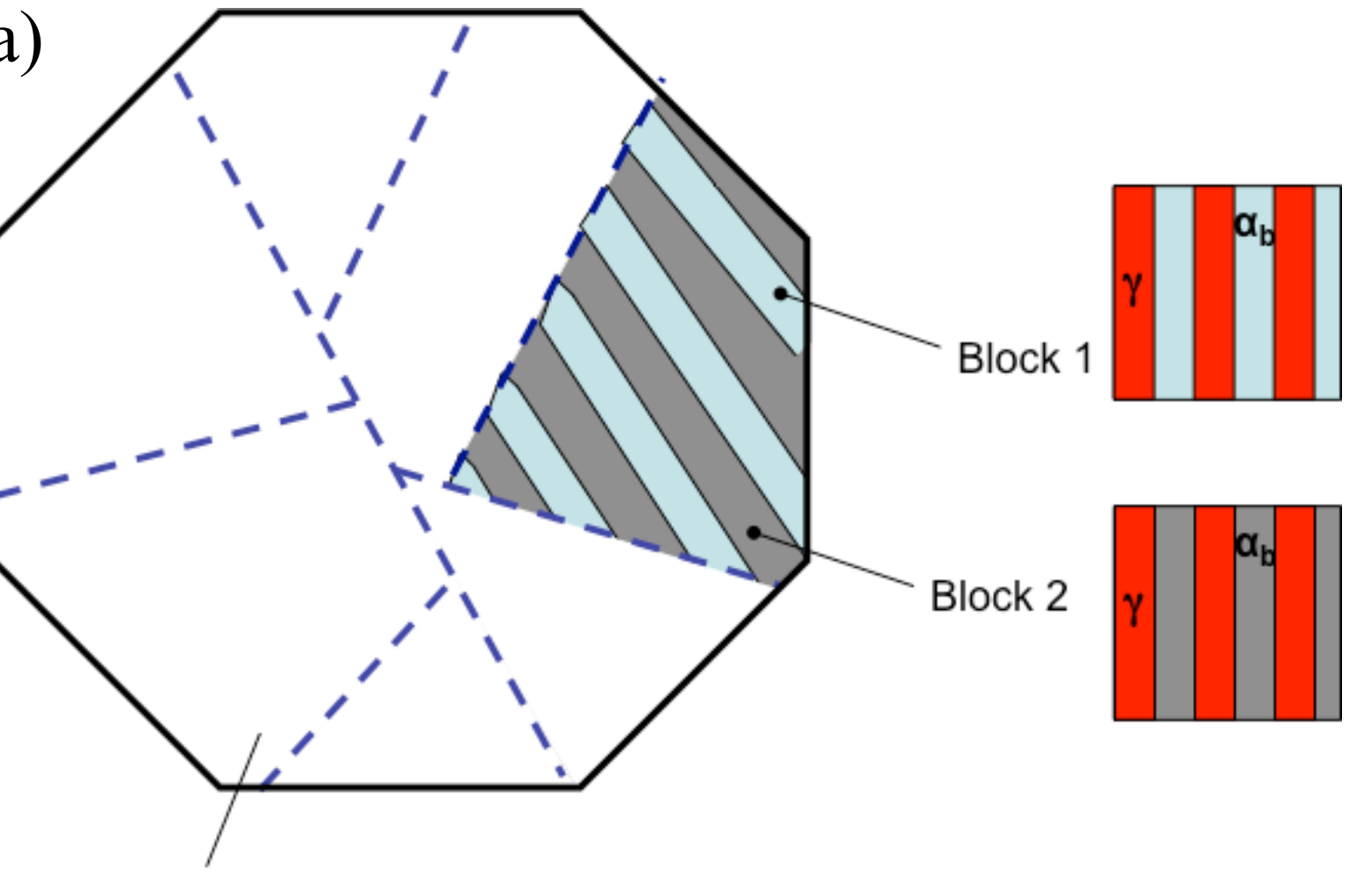

Packet

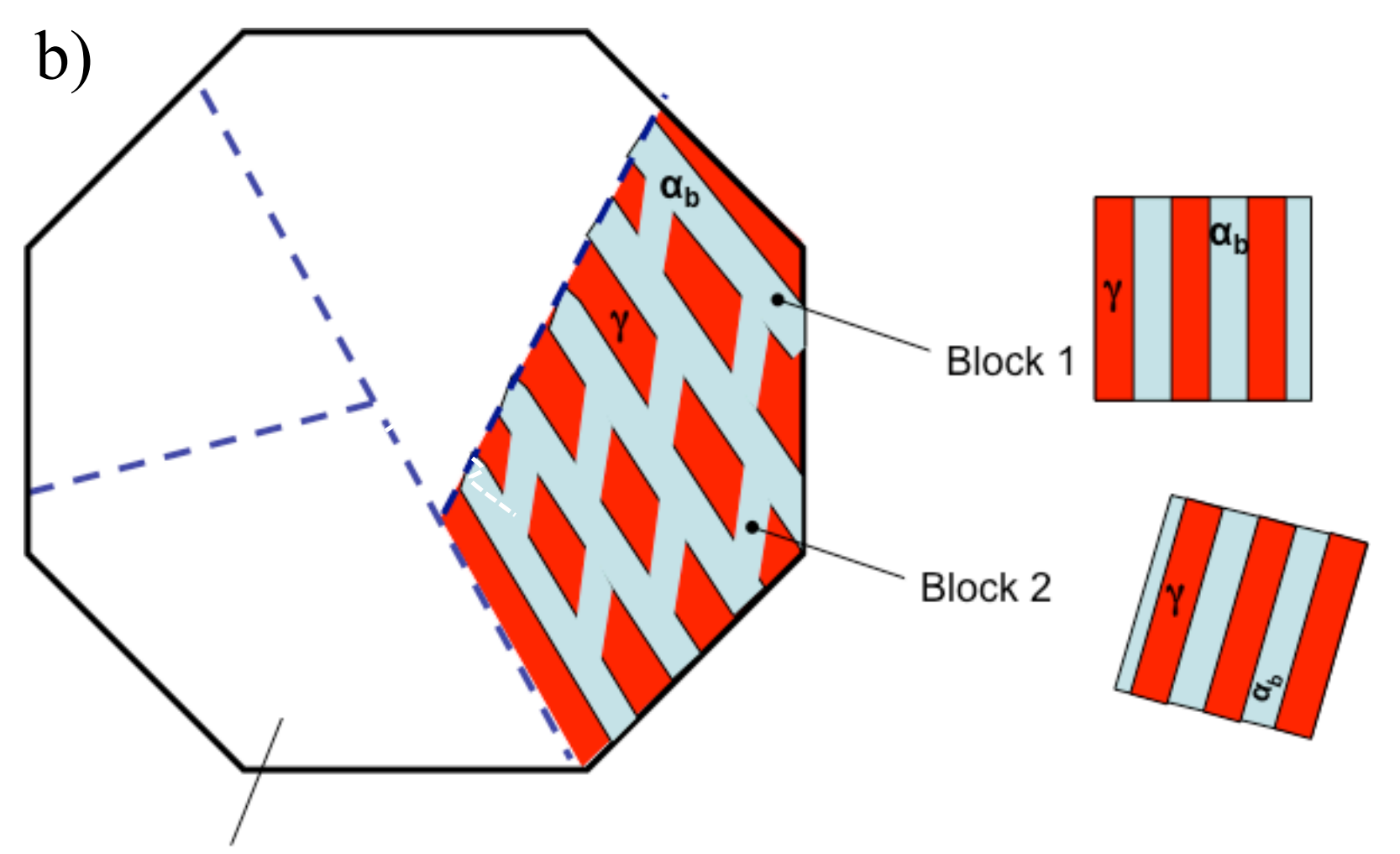

Packet

Figure 5: Schematic representation of bainitic ferrite and retained austenite arrangement in a given parent austenite grain at different bainitic transformation temperature regimes: a) $200-250^{\circ} \mathrm{C}$ and b) $300-350^{\circ} \mathrm{C}$. 


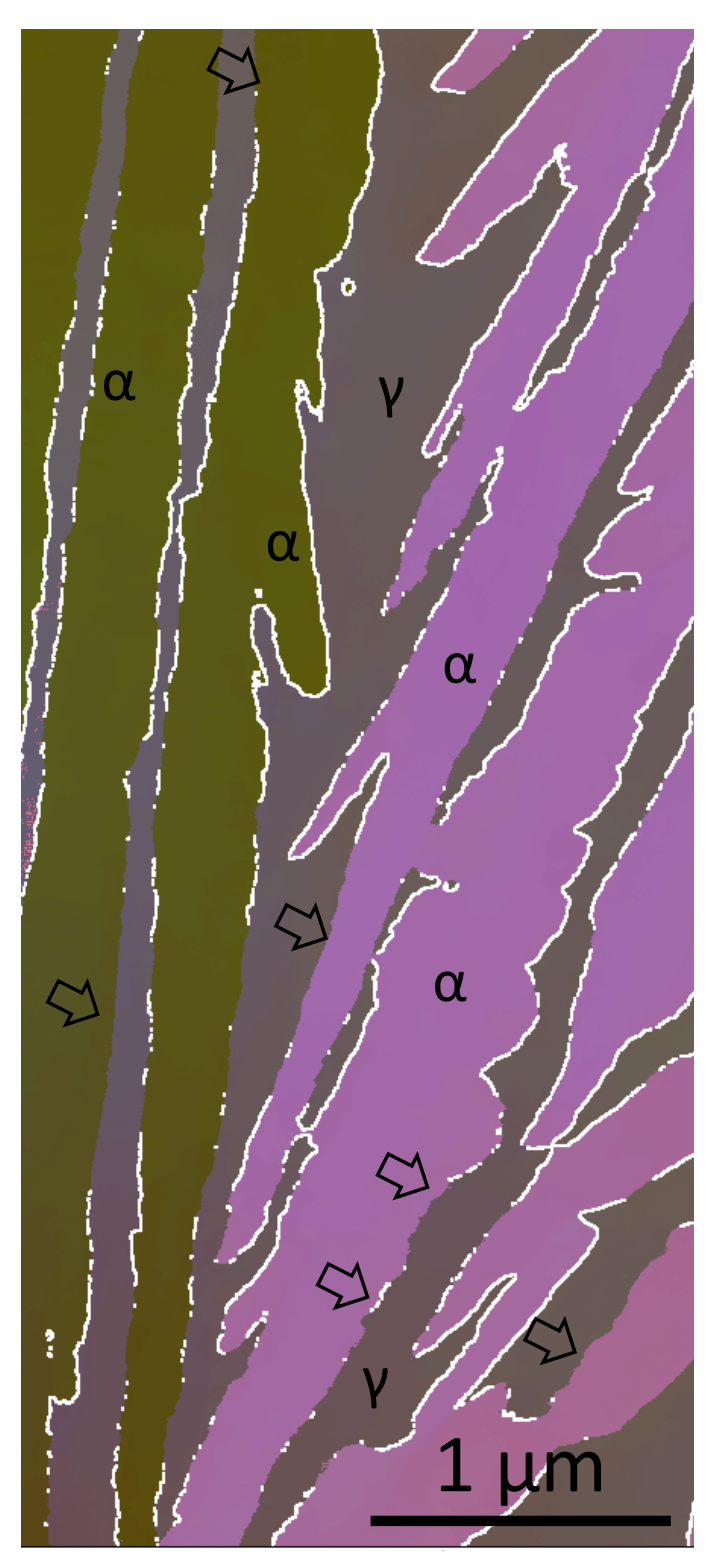

Figure 6: ASTAR image, in all Euler colouring, of bainitic structure transformed at $350^{\circ} \mathrm{C}$. White lines represent the interphase boundary having an orientation relationship close to $\mathrm{N}-\mathrm{W}$. Black arrows show the interphases with orientation relationship close to K-S. $\alpha$ and $\gamma$ represent bainitic ferrite and retained austenite, respectively. 


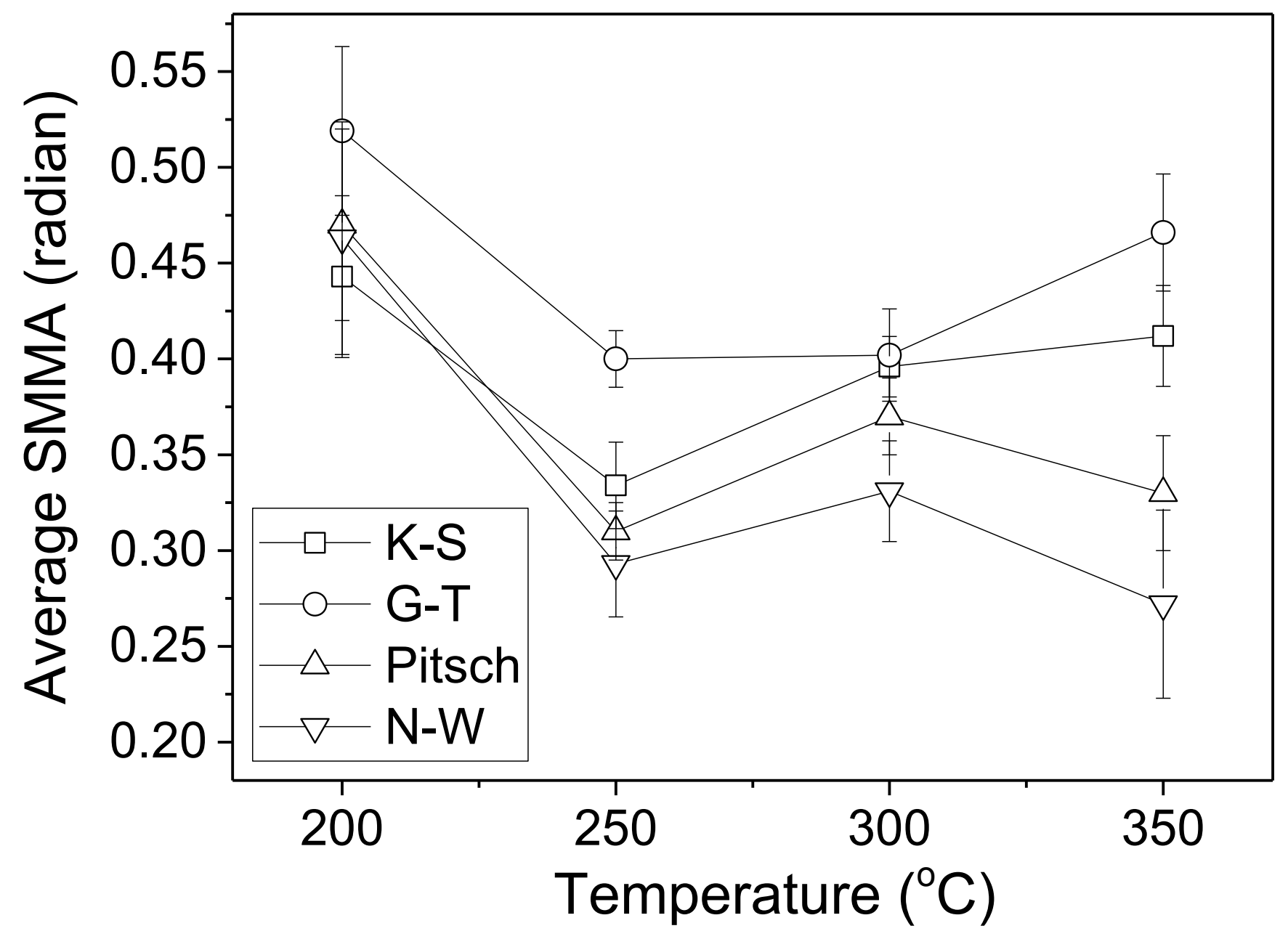

Figure 7: Average summation of mutual misorientation angle for 20 prior austenite grains as a function of bainitic transformation temperature for different potential orientation relationships. 


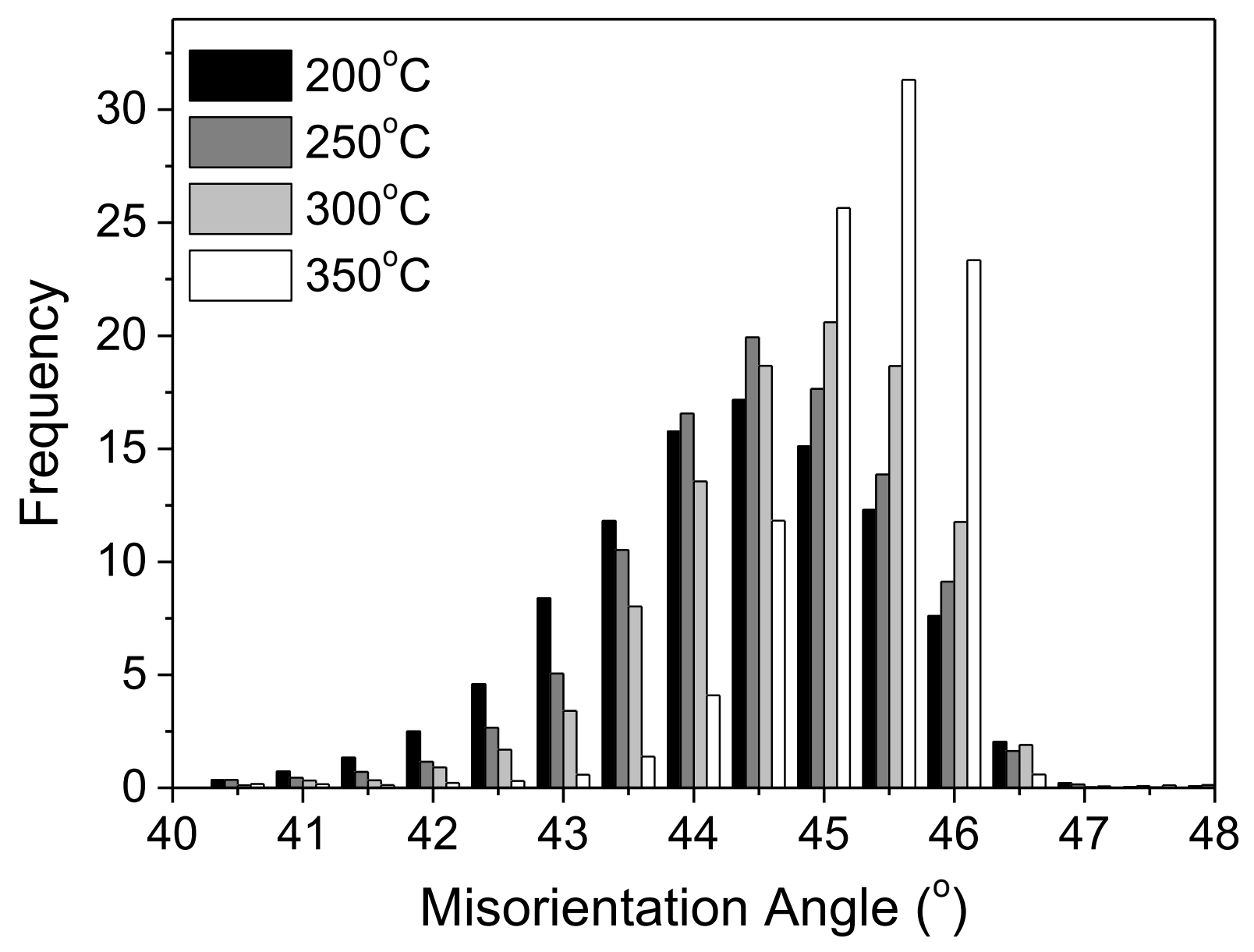

Figure 8: Misorientation angle distribution of austenite-bainitic ferrite interface at different phase transformation temperatures, based on EBSD measurements. 

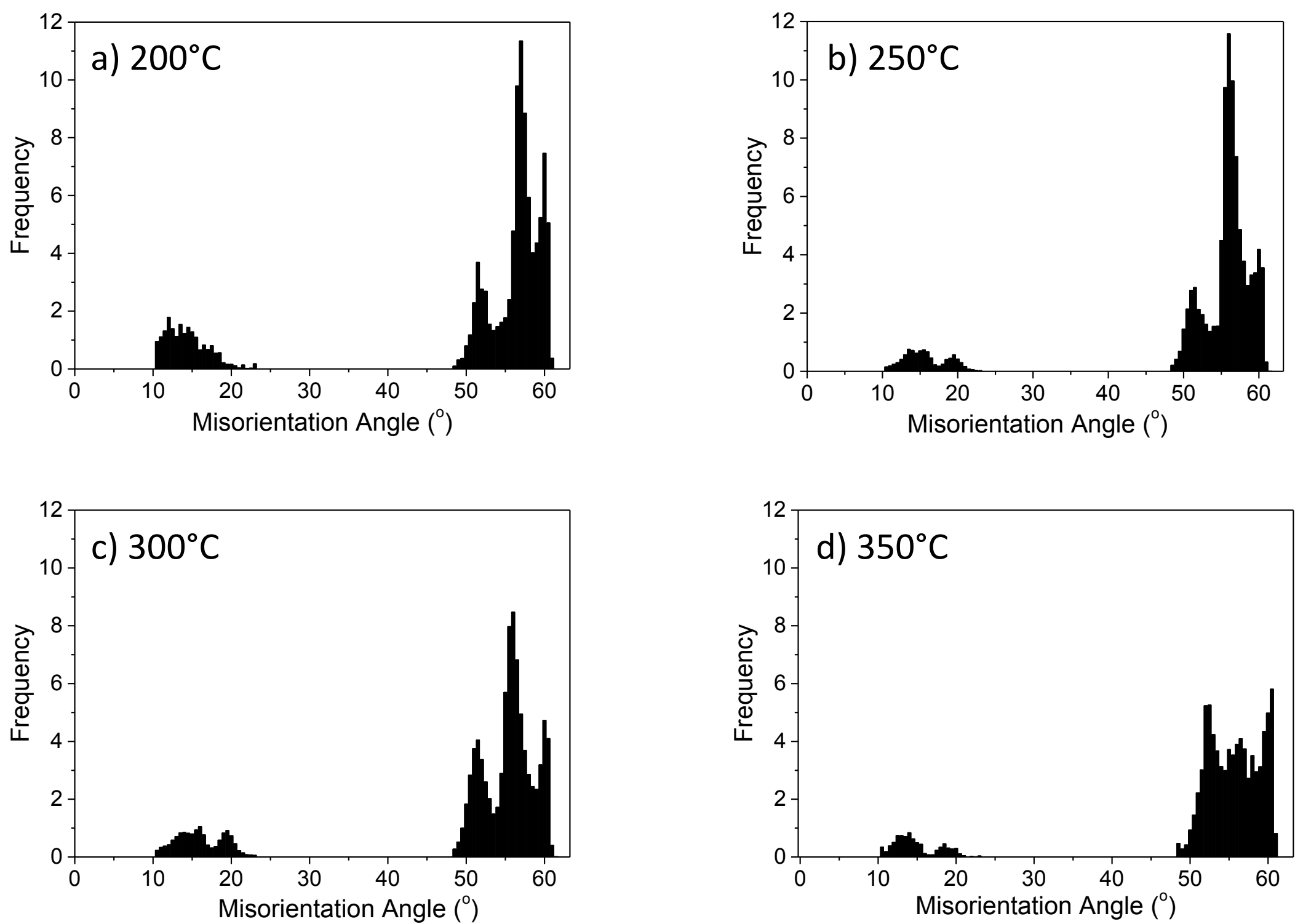

Figure 9: Misorientation angle distribution of bainitic ferrite-bainitic ferrite interface at different phase transformation temperatures. 


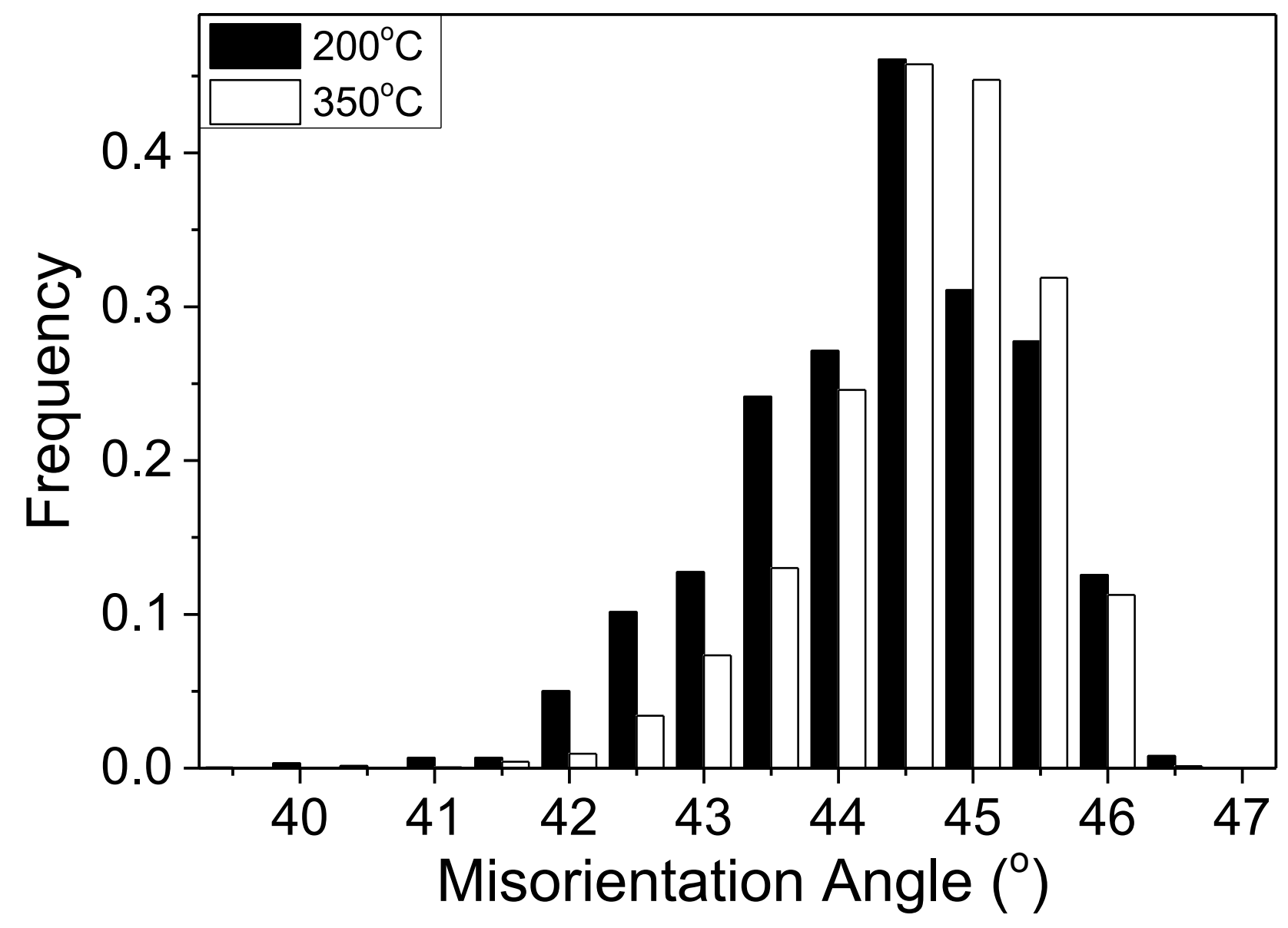

Figure 10: Misorientation angle distribution of austenite-bainitic ferrite interface at different phase transformation temperatures, based on orientation maps acquired with the NanoMegas PED system. 


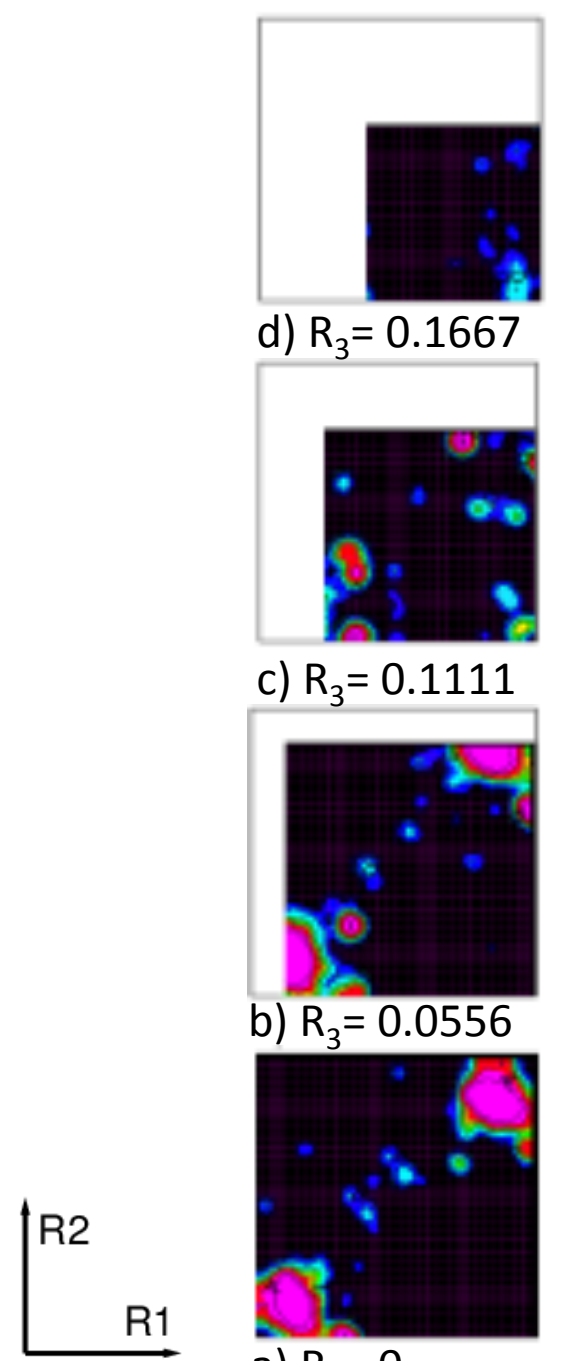

a) $R_{3}=0$
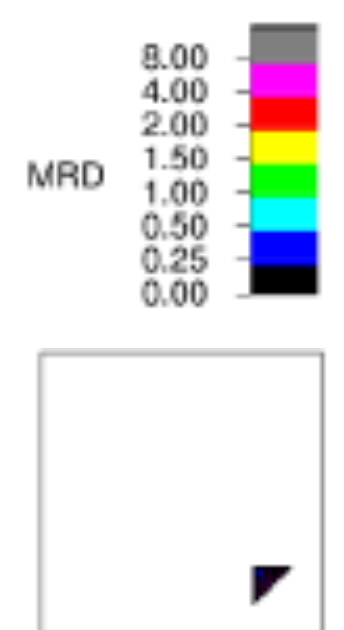

g) $R_{3}=0.3333$

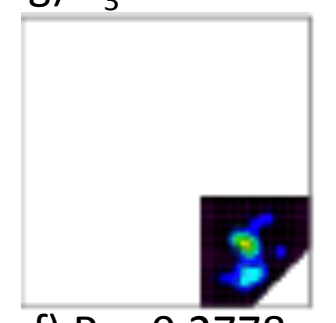

f) $R_{3}=0.2778$

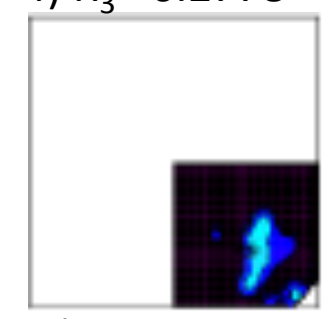

e) $R_{3}=0.2222$

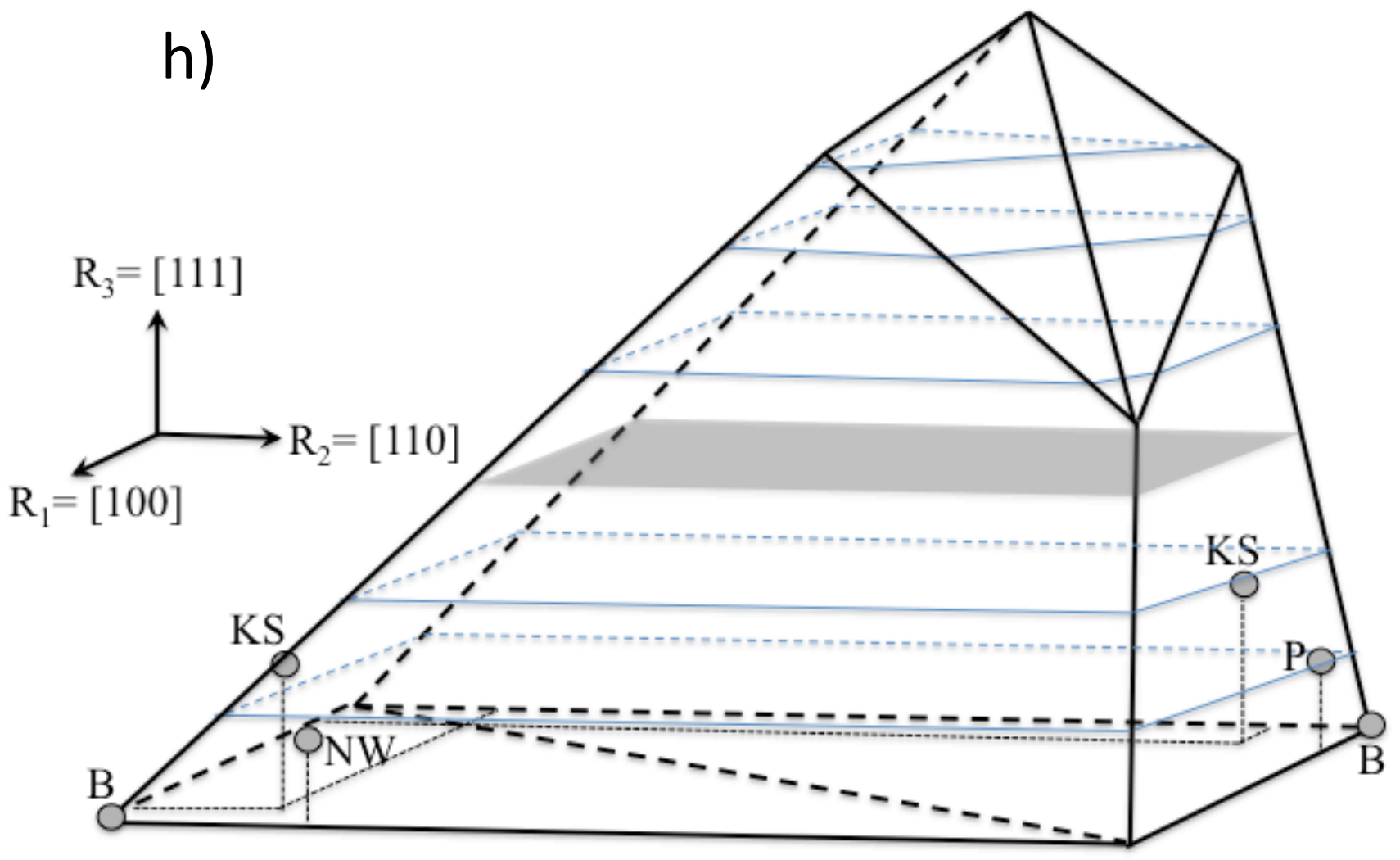

Figure 11: a) the distribution of retained austenite-bainitic ferrite interface misorientations in the three-dimensional fundamental zone in Rodrigues-Frank space in the bainitic structure transformed at $350^{\circ} \mathrm{C}$. a) projection of all data on the base of the R-F space. b-g) planar sections perpendicular to the [100] axis (i.e. $R_{3}$ ) through the fundamental zone in R-F space (h). The vertical coordinate value is below each section. MRD represents the multiples of a random distribution. B, P, KS and NW represent Bain, Pitsch, Kurdjumov-Sachs and Nishiyama-Wasserman orientation relationships. 


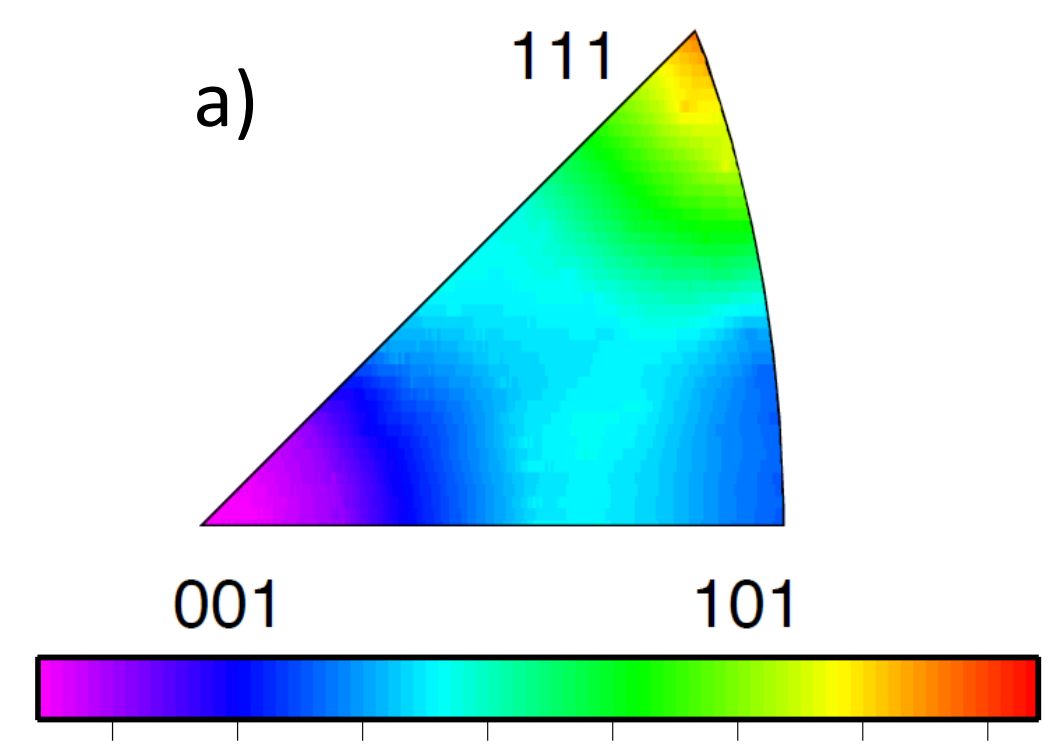

$\begin{array}{llllllll}0.60 & 0.75 & 0.90 & 1.05 & 1.20 & 1.35 & 1.50 & 1.65\end{array}$

MRD b)

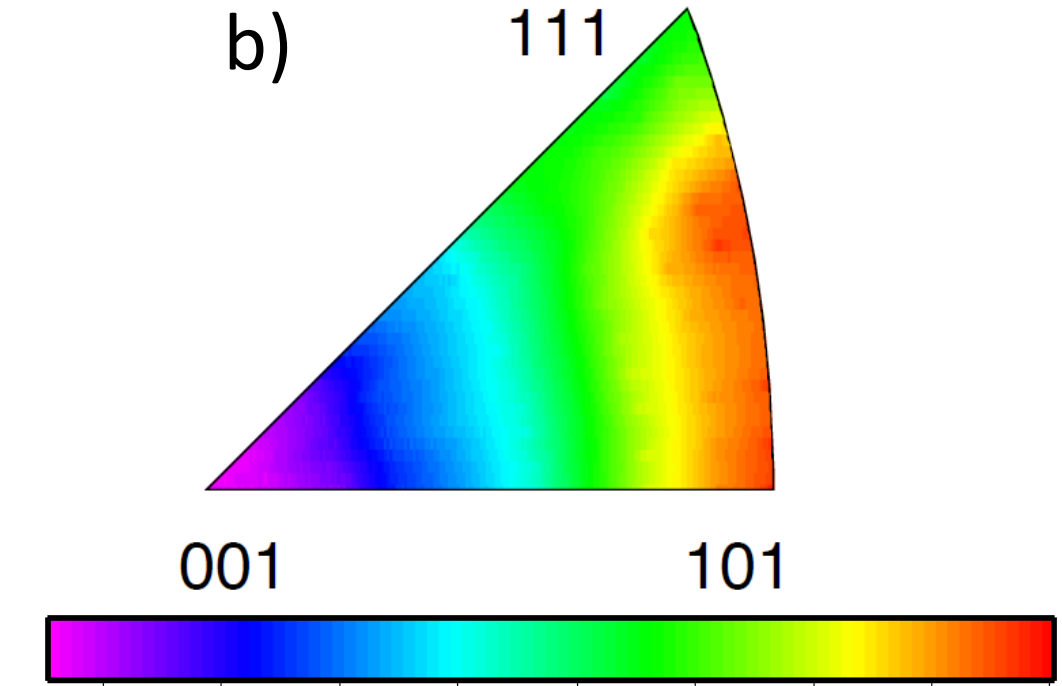

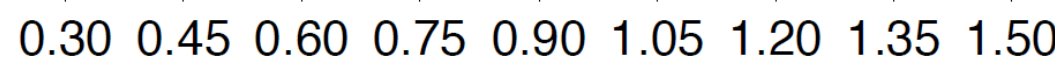

MRD

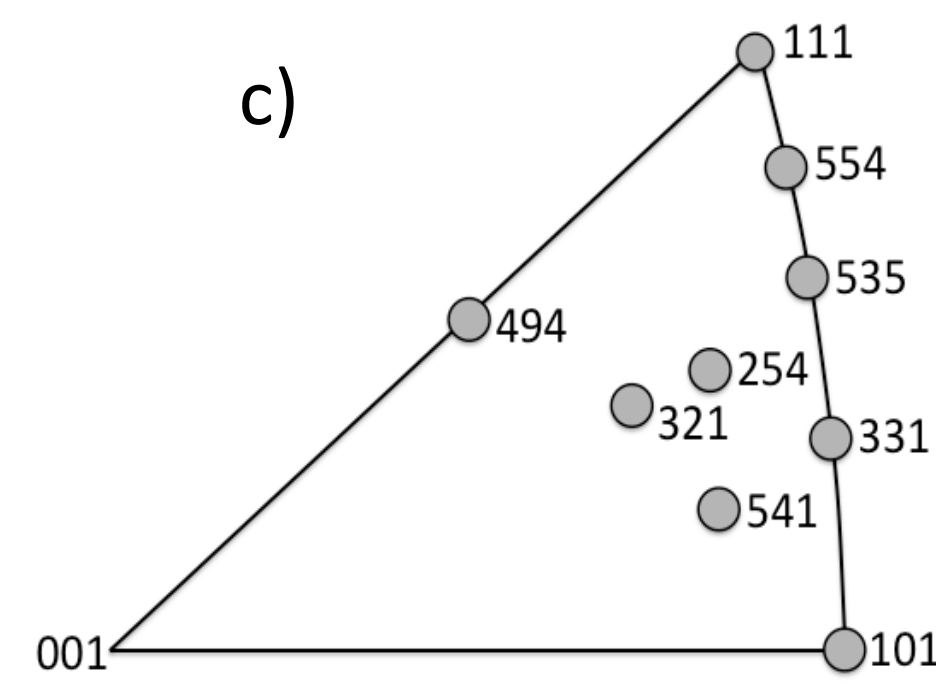

Figure 12: The relative area of planes distribution for both retained austenite (a) bainitic ferrite lath (b) interfaces at $350^{\circ} \mathrm{C}$ transformation temperature, plotted in the stereographic projection in the crystal frame independent of misorientations. c) schematic representation of measured habit plane positions in stereographic projection extracted from the literature. 
MRD

a)
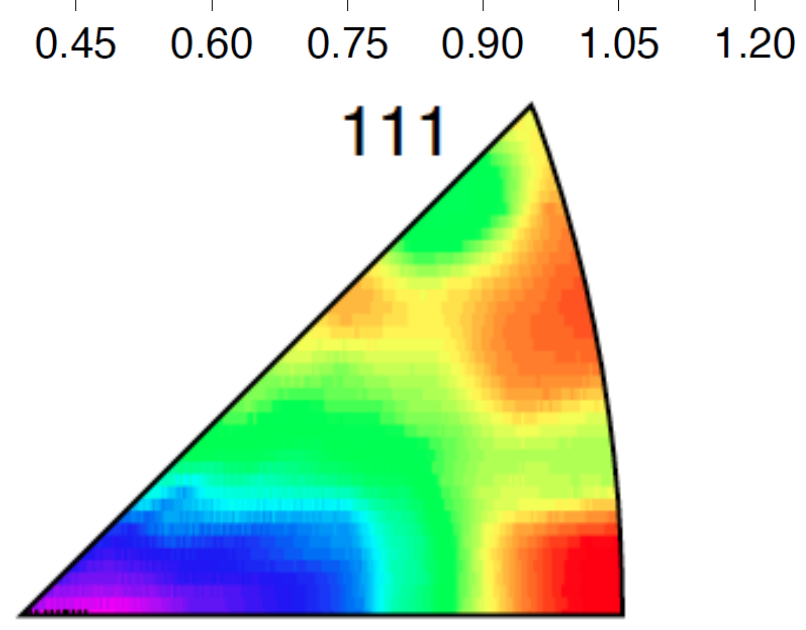

001

101

MRD

c)
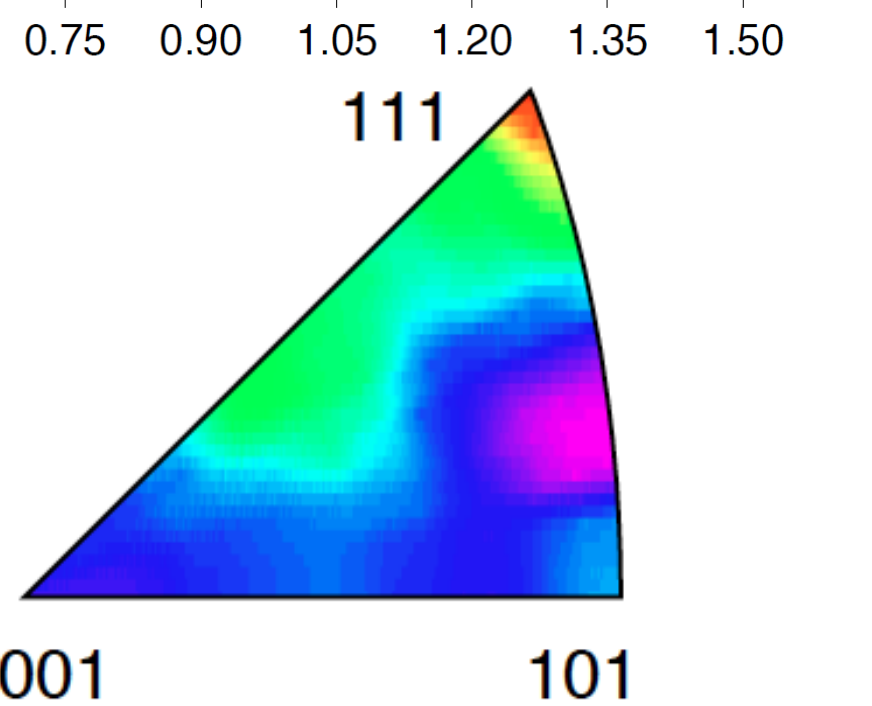

MRD

$\begin{array}{llllllll}0.45 & 0.60 & 0.75 & 0.90 & 1.05 & 1.20 & 1.35 & 1.50\end{array}$

b)

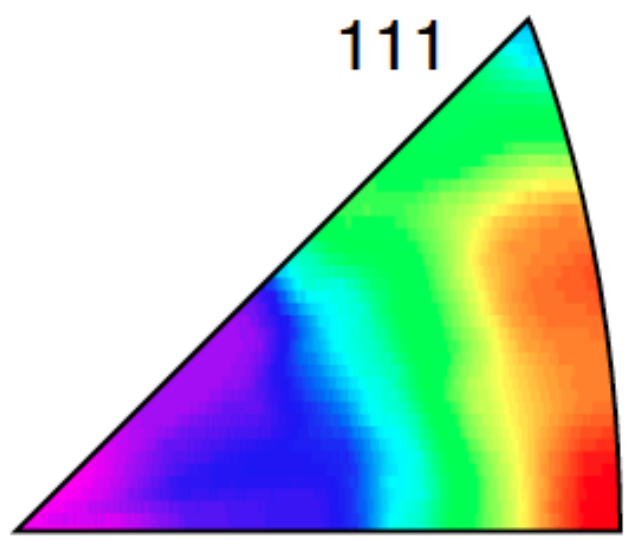

001

101

\section{MRD}

$\begin{array}{lllllllll}0.4 & 0.6 & 0.8 & 1.0 & 1.2 & 1.4 & 1.6 & 1.8 & 2.0\end{array}$

d)

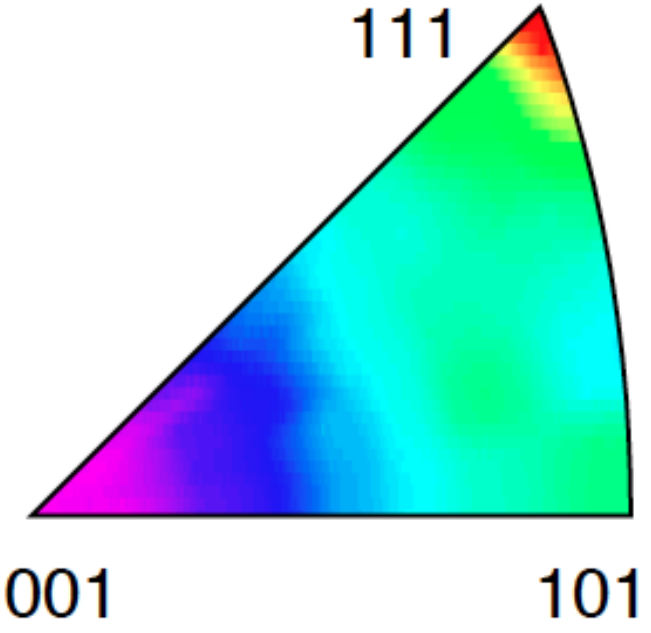

Figure 13: The relative area of planes distribution for both retained austenite and bainitic ferrite lath interfaces at $350^{\circ} \mathrm{C}$ transformation temperature, plotted in the stereographic projection in the crystal frame for different orientation relationships: a) bainitic ferrite K-S, b) bainitic ferrite N-W, c) retained austenite K-S and d) retained austenite $\mathrm{N}-\mathrm{W}$. MRD is multiples of a random distribution. 

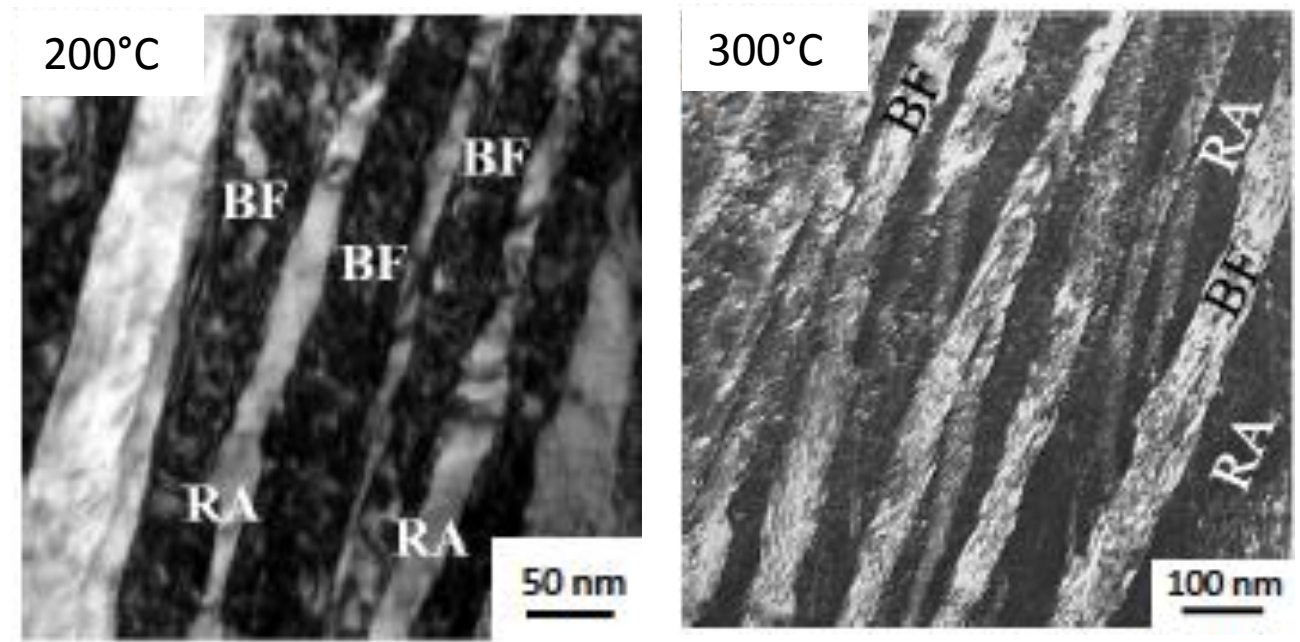

TEM images of low temperature bainite

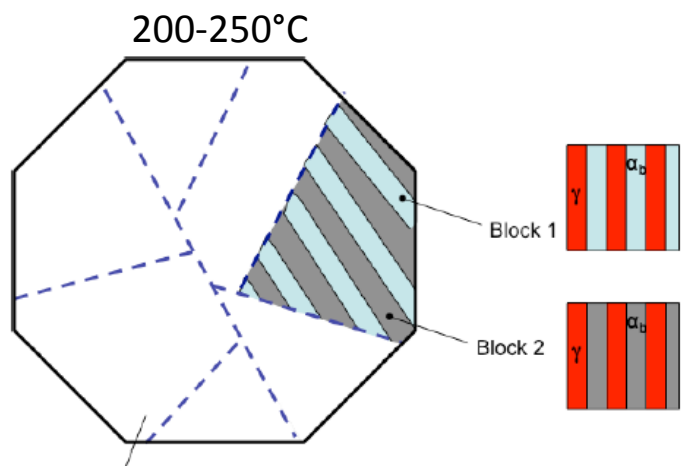

Packet

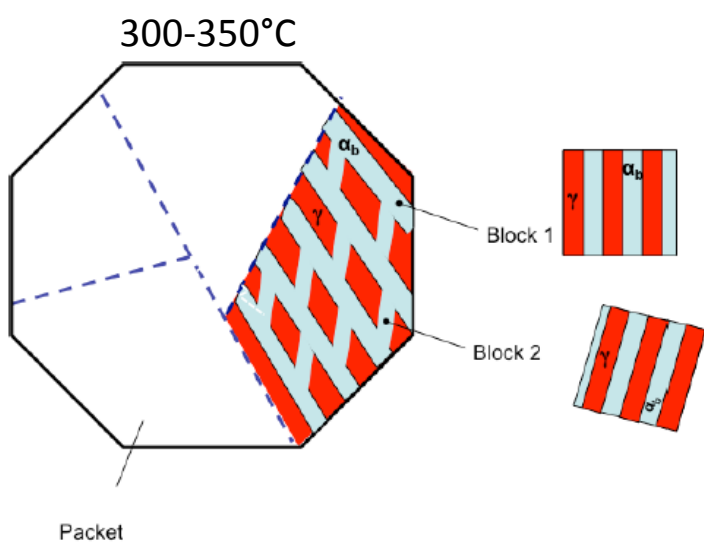

Crystallographic arrangement of low temperature bainite
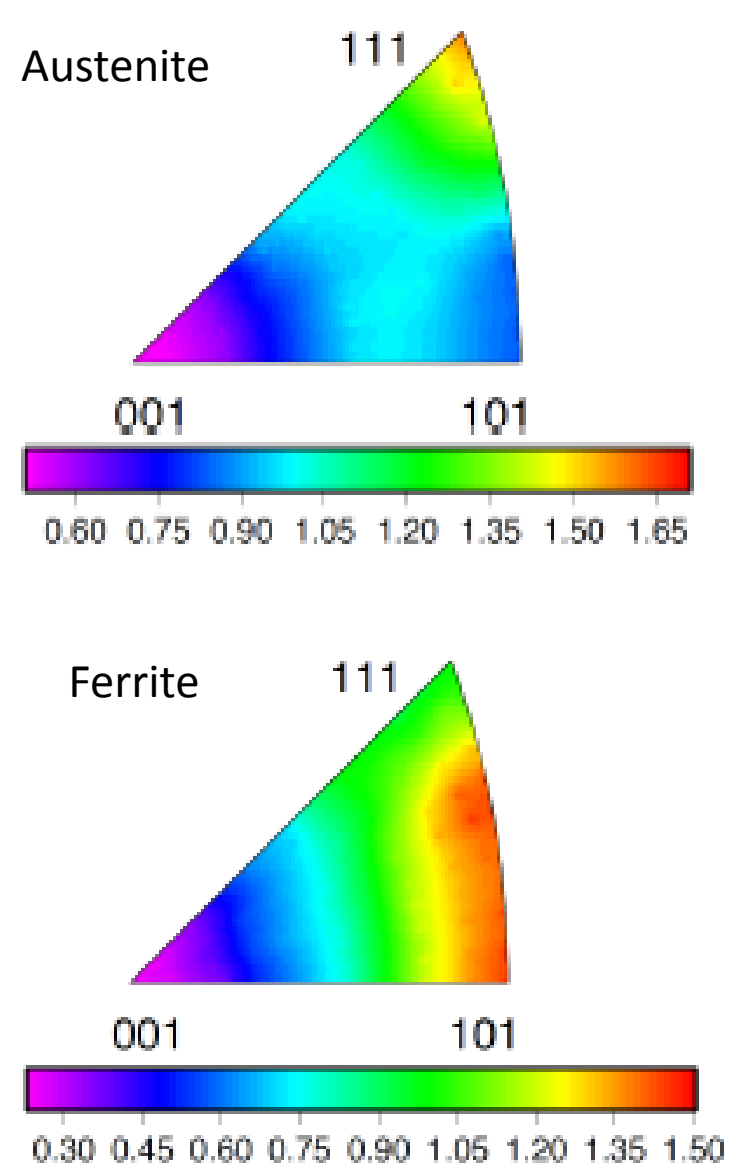

Habit Planes 